\title{
Ground-based retrieval of continental and marine warm cloud microphysics
}

\author{
G. Martucci and C. D. O'Dowd \\ School of Physics \& Centre for Climate and Air Pollution Studies, Ryan Institute, National University of Ireland Galway, \\ University Road, Galway, Ireland
}

Received: 7 June 2011 - Published in Atmos. Meas. Tech. Discuss.: 29 July 2011

Revised: 6 December 2011 - Accepted: 7 December 2011 - Published: 15 December 2011

\begin{abstract}
A technique for retrieving warm cloud microphysics using synergistic ground based remote sensing instruments is presented. The SYRSOC (SYnergistic Remote Sensing Of Cloud) technique utilises a $\mathrm{K}_{a}$-band Doppler cloud RADAR, a LIDAR (or ceilometer) and a multichannel microwave radiometer. SYRSOC retrieves the main microphysical parameters such as cloud droplet number concentration (CDNC), droplets effective radius $\left(r_{\text {eff }}\right)$, cloud liquid water content (LWC), and the departure from adiabatic conditions within the cloud. Two retrievals are presented for continental and marine stratocumulus advected over the Mace Head Atmospheric Research Station. Whilst the continental case exhibited high CDCN $\left(\bar{N}=382 \mathrm{~cm}^{-3} ; 10\right.$ th-to90th percentile [9.4-842.4] $\mathrm{cm}^{-3}$ ) and small mean effective radius $\left(\overline{r_{\text {eff }}}=4.3 ; 10\right.$ th-to-90th percentile [2.9-6.5] $\left.\mu \mathrm{m}\right)$, the marine case showed low CDNC and large mean effective radius $\left(\bar{N}=25 \mathrm{~cm}^{-3}, 10\right.$ th-to-90th percentile [1.5-69] $\mathrm{cm}^{-3}$; $\overline{r_{\text {eff }}}=28.4 \mu \mathrm{m}, 10$ th-to-90th percentile [11.2-42.7] $\left.\mu \mathrm{m}\right)$ as expected since continental air at this location is typically more polluted than marine air. The mean LWC was comparable for the two cases (continental: $0.19 \mathrm{~g} \mathrm{~m}^{-3}$; marine: $0.16 \mathrm{~g} \mathrm{~m}^{-3}$ ) but the 10 th-90th percentile range was wider in marine air (continental: $0.11-0.22 \mathrm{~g} \mathrm{~m}^{-3}$; marine: $0.01-$ $0.38 \mathrm{~g} \mathrm{~m}^{-3}$ ). The calculated algorithm uncertainty for the continental and marine case for each variable was, respectively, $\sigma_{N}=161.58 \mathrm{~cm}^{-3}$ and $12.2 \mathrm{~cm}^{-3}, \sigma_{r_{\text {eff }}}=0.86 \mu \mathrm{m}$ and $5.6 \mu \mathrm{m}, \sigma_{\mathrm{LWC}}=0.03 \mathrm{~g} \mathrm{~m}^{-3}$ and $0.04 \mathrm{~g} \mathrm{~m}^{-3}$. The retrieved $\mathrm{CDNC}$ are compared to the cloud condensation nuclei concentrations and the best agreement is achieved for a supersaturation of $0.1 \%$ in the continental case and between $0.1 \%$ $0.75 \%$ for the marine stratocumulus. The retrieved $r_{\text {eff }}$ at the top of the clouds are compared to the MODIS satellite $r_{\text {eff }}$ : $7 \mu \mathrm{m}$ (MODIS) vs. $6.2 \mu \mathrm{m}$ (SYRSOC) and $16.3 \mu \mathrm{m}$ (MODIS)
\end{abstract}

Correspondence to: G. Martucci (giovanni.martucci@nuigalway.ie) vs. $17 \mu \mathrm{m}$ (SYRSOC) for continental and marine cases, respectively. The combined analysis of the CDNC and the $r_{\text {eff }}$, for the marine case shows that the drizzle modifies the droplet size distribution and $\overline{r_{\text {eff }}}$ especially if compared to $r_{\text {eff }}^{\mathrm{MOD}}$. The study of the cloud subadiabaticity and the LWC shows the general sub-adiabatic character of both clouds with more pronounced departure from adiabatic conditions in the continental case than in the marine.

\section{Introduction}

At the global scale clouds increase the reflection of incoming solar radiation from $15 \%$ to $30 \%$ with an overall forcing of about $-44 \mathrm{~W} \mathrm{~m}^{-2}$. On the other hand, the reduced cloud thermal emission below clear-sky values enhances the cloud greenhouse effect by about $31 \mathrm{~W} \mathrm{~m}^{-2}$ thus determining a net cooling effect of about $13 \mathrm{~W} \mathrm{~m}^{-2}$ (Ramanathan et al., 1989). The determination of the global cloud radiative forcing intended as the difference between the radiation budget components for cloudy conditions and clear-sky conditions is a challenging task which remains affected by a large uncertainty. The increase in global surface temperature of $0.6^{\circ} \mathrm{C}$ that occurred in the last century corresponds to a change of less than $1 \%$ in the radiative energy balance between short wave (SW) absorption and long wave (LW) emission from the Earth system (Kaufman et al., 2002). Despite the critical role of this energy mechanism, the balance between cooling and warming effect due to LW and SW net fluxes in cloudy regions remains one of the largest uncertainties when assessing the aerosol indirect effect. The fact that the greenhouse effect due to cloud is orders of magnitude larger than the one that would result from a hundredfold increase in $\mathrm{CO}_{2}$ mixing ratio as well as the fact that hydrometeors size and concentration affect the cloud albedo are amongst the primarily reasons why in the last $50 \mathrm{yr}$ studying cloud microphysics became paramount in order to understand climate changes.

Published by Copernicus Publications on behalf of the European Geosciences Union. 
Numerical models and observations can improve the knowledge of cloud microphysics both at global and regional scale; especially for the description of cloud formation, numerical simulations at the regional and micro-scale (cloud-resolved scale) permit to resolve with explicit integration schemes the cloud microphysical processes and to assess the aerosol indirect effect. On the other hand, cloud and aerosols observations can either be in situ or remotely sensed. In situ measurements represent typically a reference for the microphysical variables retrieved using ground-based remote sensing instrumentation. The need of references becomes important especially when the microphysics is retrieved by the remote sensing instrumentation using integrated profiles and combined methods based on multiple sensors which introduce a number of assumptions and large uncertainty. In situ observations of cloud microphysical parameters are limited by both the cost of performing the measurements and the availability of the infrastructures. Ground-based remote sensing instrumentation can perform the retrieval of cloud microphysics with cost-effective and continuous measurements. An efficient system of measurements must ensure the operational retrieval of the main cloud microphysics parameters such as cloud droplet number concentration (CDNC), effective radius $\left(r_{\text {eff }}\right)$, liquid water content (LWC) and the albedo. Indeed, the albedo controls the amount of reflected and absorbed solar radiation and is then responsible for the mechanisms that initiates, maintains or inhibits the global cooling/warming. Alteration of the cloud albedo can occur by anthropogenic action: seeding experiments on marine stratus clouds by controlled release of aerosols (Durkee et al., 2000; Salter et al., 2008; Korhonen et al., 2010) demonstrate the capability to modify the cloud albedo and to alter the cloud forcing at local scales. The cloud albedo is non-linearly related to the cloud thickness, the LWC and the CDNC (Ackerman et al., 2000; Seinfeld and Pandis, 2006). The level of water vapour supersaturation and the number of cloud condensation nuclei $(\mathrm{CCN})$ is also indirectly related to the cloud albedo. In polluted air the number of $\mathrm{CCN}$ is supposed to increase rapidly leading to increased CDNC (Twomey, 1977), nevertheless the efficiency in activating $\mathrm{CCN}$ into $\mathrm{CDNC}$ depends on a number of factors including $\mathrm{CCN}$ size, chemical compositions and cloud dynamics (updraft and downdraft). There are instead no evidences of the impact of the entrainment-mixing on the activation process, although recent studies indicate homogeneous and inhomogeneous mixing as depleting mechanism for CDNC formation especially in warm cumuli (e.g. Morales et al., 2011). Several studies in the last two decades showed different methodologies capable to retrieve some microphysical parameters of liquid clouds by means of both independent and synergistic remote sensing instrumentation (Fox and Illingworth, 1997; Dong et al., 1997; Boers et al., 2000, 2006; Liljegren et al., 2001; Dong and Mace, 2003; Illingworth et al., 2007; Turner et al., 2007; Brandau et al., 2010). None of the cited methodologies, however, provide the full set of microphys- ical parameters (i.e. LWC, CDNC and $r_{\text {eff }}$ ). The state-ofthe-art suggests that using synergistic information from passive and active co-located remote sensors can provide sufficient cloud input parameters in order to retrieve cloud microphysics with only a few assumptions. A synergistic suite of remote sensors, namely a $\mathrm{K}_{a}$-band Doppler cloud RADAR, a LIDAR-ceilometer and a multichannel microwave radiometer (MWR) installed at the GAW Atmospheric Station of Mace Head, Ireland, has been used to provide the input data to the SYRSOC (SYnergistic Remote Sensing Of Cloud) multi-module technique and to retrieve the three primary microphysical parameters from liquid clouds. In addition to the three main microphysical variables, SYRSOC can provide a number of parameters describing the cloud droplet spectral properties (relative dispersion) and cloud degree of subadiabaticity. SYRSOC has been applied to two cases of warm stratocumulus clouds formed in continental and marine air to analyze how the different air masses and aerosol load influence the cloud microphysics in determining CDNC, $r_{\mathrm{eff}}$, LWC.

\section{Site, instruments and cases selection}

\subsection{The site}

Located on the west coast of Ireland, the Atmospheric Research Station at Mace Head (O'Connor et al., 2008), Carna, County Galway is unique in Europe in that its location offers westerly exposure to the North Atlantic Ocean through the clean sector $\left(190^{\circ} \mathrm{N}-300^{\circ} \mathrm{N}\right)$ and the opportunity to study atmospheric composition under northern hemispheric background conditions as well as European continental emissions when the winds favour transport from that region. The site location $\left(53^{\circ} 20^{\prime} \mathrm{N}\right.$ and $\left.9^{\circ} 54^{\prime} \mathrm{W}\right)$ is in the path of the midlatitude cyclones which frequently traverse the North Atlantic. The instruments are located $300 \mathrm{~m}$ from the shore line on a gently-sloping hill ( $4^{\circ}$ incline $)$.

\subsection{The instruments}

The CLOUDNET programme (Illingworth et al., 2007) has aimed to provide near-continuous and near-real-time cloud properties for both forecasting objectives and for advancing of cloud-climate interactions. CLOUDNET promotes the synergistic retrieval of cloud properties from a combination of three instruments, namely a LIDAR (or a ceilometer), a microwave humidity and temperature profiler and a K- to E-band cloud RADAR. The Atmospheric Station of Mace Head is part of the CLOUDNET programme since 2009; data from the Jenoptik CHM15K LIDAR ceilometer (Heese et al., 2010; Martucci et al., 2010a) with 1064-nm wavelength and $15-\mathrm{km}$ vertical range, the RPG-HATPRO (Crewell and Löhnert, 2003; Löhnert and Crewell, 2003; Löhnert et al., 2009) water vapour and oxygen multi-channel microwave profiler and the MIRA36, $35 \mathrm{GHz} \mathrm{K}_{a}$-band Doppler 
cloud RADAR (Bauer-Pfundstein and Goersdorf, 2007; Melchionna et al., 2008) are used to retrieve the cloud microphysics using SYRSOC and CLOUDNET.

\subsection{Case selection}

Cases are selected based on SYRSOC requirements, namely: (1) the studied cloud layer must be unique along the atmospheric column to ensure that the MWR-retrieved Liquid Water Path (LWP) belongs entirely to the studied cloud; (2) even though many clouds remain in the liquid state even when they form well above the freezing height (Mason, 1971; Pruppacher and Klett, 1978), the cloud layer should be located no more than $1000 \mathrm{~m}$ above the freezing level $\left(\sim-6.5^{\circ} \mathrm{C}\right.$ in standard atmosphere) and preferably below it; (3) liquid precipitation (LWP $>1000 \mathrm{~g} \mathrm{~m}^{-2}$ ), must be avoided for a correct interpretation of the MWR data (Löhnert and Crewell, 2003). If they occur, short rain events must be excluded for the microphysical analysis. On the other hand, SYRSOC has no limitations working in drizzle, which represents an advantage when dealing with stratocumulus forming in marine air characterized by large droplets growing fast by coalescence and forming drizzle in most of the cases. Care must be used when studying drizzle clouds in order to include the area with drizzle within the actual cloud boundaries (see Sect. 3.1). In fact, the contribution of drizzle to the total liquid water must be always considered in order to avoid errors in the final calculation of the cloud liquid water content. Based on these requirements two cases of liquid clouds have been selected for which the air masses originated from opposite sectors (Fig. 1): a continental drizzle-free stratiform cloud (28 May 2008) and a marine stratiform cloud with drizzle (10 December 2010). In-situ observations have been used to compare the microphysics retrieved by SYRSOC with satellite $r_{\text {eff }}$ and CCN sampled at the ground level.

\section{Physics of SYRSOC}

SYRSOC retrieves the microphysics of liquid clouds providing CDNC, $r_{\text {eff }}$, relative dispersion and LWC. SYRSOC is a three-level algorithm (Fig. 2) acquiring off-line input data from the same suite of instrument as CLOUDNET. At each level SYRSOC generates microphysical outputs which are used for the next computational level: the first level's outputs consist of the cloud boundaries, the LIDAR extinction and the cloud subadiabaticity. The three outputs are calculated using the reflectivity from the cloud RADAR, the attenuated backscatter from the LIDAR and the temperature and the integrated cloud liquid water from the MWR. The second level's output is the CDNC from the LIDAR extinction, the cloud depth and the cloud subadiabaticity. The third level's outputs are the $r_{\text {eff }}$ and the cloud LWC - both of which are retrieved using the $\mathrm{CDNC}$, the level of cloud subadiabaticity and the droplet size distribution.

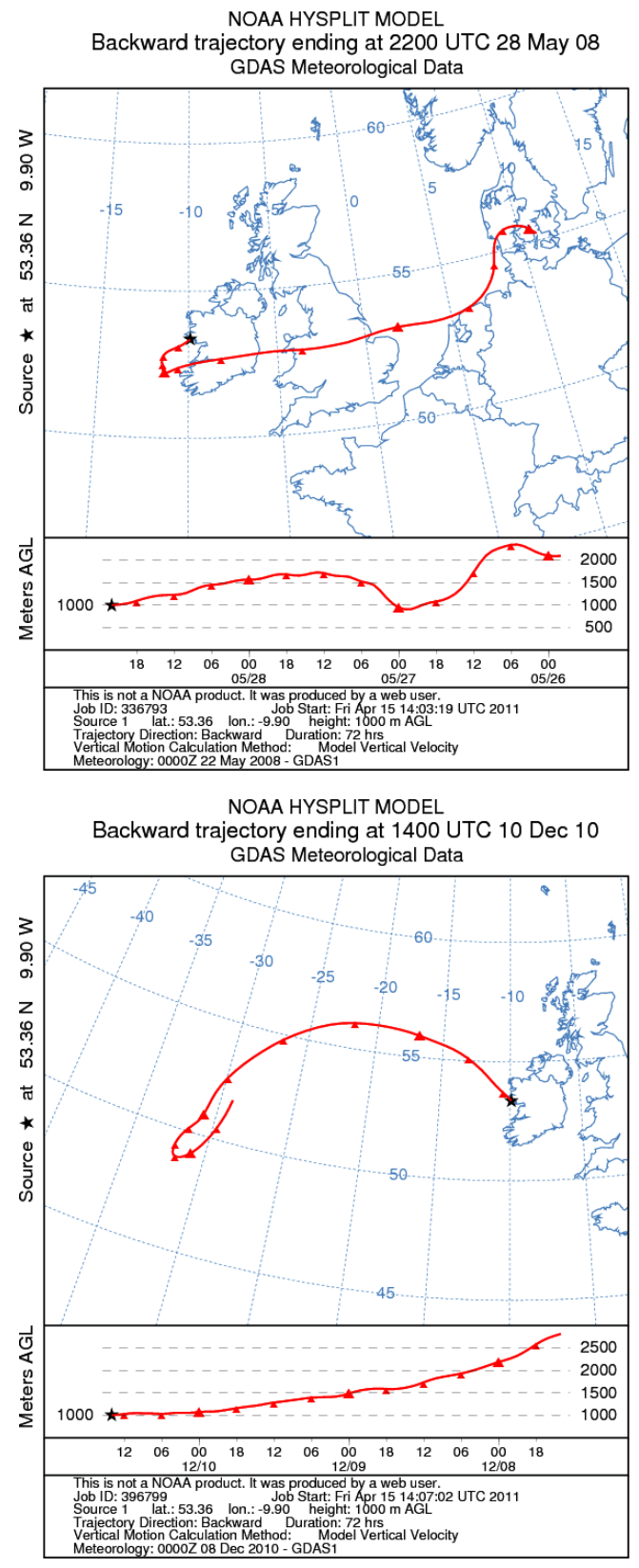

Fig. 1. 72-h backward trajectories (BT) calculated by NOAA HYSPLIT model and based on GDAS Meteorological 1000-m BT on 28 May 2008 (left) and 10 December 2010 (right).

\subsection{Level 1: cloud boundaries determination}

Detection of the cloud boundaries plays an important role in the retrieval of cloud microphysics. Errors of few tens of meters in the detection of the cloud base can lead to errors in the calculation of the CDNC. The extinction efficiency $Q$, which will appear in the equation to calculate the CDNC, is sensitive to the cloud base height, its value quickly responds to variations in the droplet size at the cloud base. $Q$ can be regarded as constant only when the mode of the size 


\section{SYRSOC: SYnergistic Remote Sensing Of Cloud}

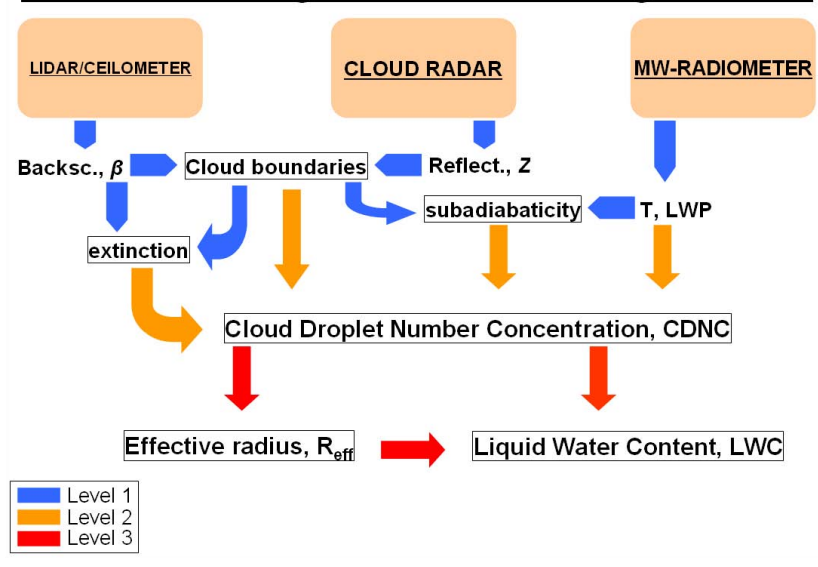

Fig. 2. Outline of SYRSOC: three-level (blue-orange-red) retrieval scheme of cloud microphysical variables.

distribution exceeds $1 \mu \mathrm{m}$, i.e. the cloud base has to be carefully detected in order not to include large aerosols below the real cloud base. In drizzle-free conditions, the LIDAR (and ceilometer) is the optimal remote sensor to detect the cloud base, while the cloud RADAR is more reliable to provide the cloud top and the lower boundary of drizzle below the LIDAR-detected cloud base. The automated algorithm Temporal Height Tracking, THT, (Martucci et al., 2010a, b) has been developed to detect the cloud base and top with high accuracy. For this study the THT algorithm has been applied to the LIDAR and RADAR profiles to determine the cloud boundaries.

\subsection{Level 1: LIDAR extinction}

The LIDAR extinction is expressed in terms of the extinction coefficient $\sigma(z)$ calculated by inverting the 1.064- $\mu \mathrm{m}$ LIDAR profiles (Klett, 1981; Ferguson and Stephens, 1983) in the lower part of the cloud where the LIDAR signal is not completely attenuated, i.e. 100 up to $200 \mathrm{~m}$ above the cloud base (depending on the cloud optical thickness). LIDAR calibration for molecular signal component is essential to invert the LIDAR signal; it is performed between 4 and $8 \mathrm{~km}$ above the LIDAR receiver preferably during night and for integration time not shorter than $1 \mathrm{~h}$. The LIDAR has been calibrated in clear-sky condition by a multi-wavelength sun photometer at the extrapolated wavelength of $1.064 \mu \mathrm{m}$, the LIDAR return has then been inverted between cloud base and top assuming a LIDAR ratio of $S=18.2 \pm 1.8 \mathrm{sr}$ (Pinnick et al., 1983). The assumed constant LIDAR ratio affects the derivation of the extinction by propagating through the stable solution obtained by Klett (1981, Eq. 9). Because the numerical procedure used in this study to invert the LIDAR return (Ferguson and Stephens, 1983) is normalized by $S$, the microphysical variables retrieved in the following sections are physically independent of $S$. However, as the LIDAR return is mathematically divided by $S$, the $S$-error propagates to the extinction and to the other determinations and must be considered when assessing the total uncertainty. In order to use the entire extinction profile to retrieve the CDNC a curve fit is used to regress in least-squares sense the not-fully-attenuated part of the $\sigma$-profile and to extrapolate the $\sigma$-points (and then the CDNC) in the fully-attenuated region (see Sect. 3.4).

\subsection{Level 1: subadiabaticity}

In adiabatic conditions the LWC increases linearly from the base to the top of the cloud. In order to provide a realistic representation of the liquid water profile through liquid clouds, a subadiabatic function is considered to describe the adiabatic departure at each height $z$ :

$\operatorname{LWC}(z)=\frac{4}{3} \pi \rho_{\mathrm{W}} N(z)\left\langle r^{3}(z)\right\rangle=f(z) A_{\mathrm{ad}} z$

The middle term in Eq. (1a) is proportional to the concentration of cloud droplets $N$ ( $N$ indicates CDNC in all equations) and to the third moment of the droplets size distribution (DSD). The term on the far-right introduces the subadiabatic function $f(z)$ which depends on the height $z$ along the cloud layer and which modifies the vertical gradient of the adiabatic LWC, $A_{\mathrm{ad}}$, by providing the subadiabatic departure along the LWC profile. Different approaches to calculate the departure function $f(z)$ have been suggested in the recent literature (Boers et al., 2000, 2006; Brandau et al., 2010): an expression for $f(z)$ can be set up starting from the far-right term in Eq. (1a) in saturated irreversible pseudoadiabatic conditions:

$\operatorname{LWC}(z)=D \cdot A(z)_{\mathrm{SAT}} z$

Here, the term $D$ is a correction factor related to the subadiabaticity and whose meaning will become clear with Eq. (2). The term $A_{\mathrm{SAT}}$ is the vertical rate of change of condensable water during a saturated irreversible pseudoadiabatic process (Iribarne and Godson, 1973; Pruppacher and Klett, 1978) and depends on the temperature vertical profile through the cloud. Combining Eq. (1a) and (1b) we obtain the expression of the departure function $f(z)$ :

$f(z)=\frac{D \cdot A_{\mathrm{SAT}}(z)}{A_{\mathrm{ad}}}$

In contrast to the gradient $A_{\text {ad }}$, which has a constant value with height, $A_{\mathrm{SAT}}$ slowly varies with height from cloud base to cloud top and is a function of temperature and humidity. The change in condensable water in saturated conditions is then better represented by $A_{\mathrm{SAT}}=A_{\mathrm{SAT}}(T(z), P(z))$ which can be calculated directly using the temperature from the MWR. Numerical derivation of the main parameters involved to calculate the dependence of $A_{\mathrm{SAT}}$ on the pressure, $P$, and the saturation vapour pressure, $e_{\mathrm{s}}$, can be obtained 
from the parameterizations suggested by, amongst others, Richards (1971) and Rogers and Yau (1989).

In order to obtain $f(z)$, the correction factor $D$ must be determined by integration of Eq. (1b) over the cloud thickness. The measured LWP can then be used to obtain an expression for $D$ :

$$
\begin{aligned}
\mathrm{LWP} & =D \int_{z_{\mathrm{b}}}^{z_{\mathrm{t}}} A_{\mathrm{SAT}}(z) z d z=D\left[\left[A_{\mathrm{SAT}}(z) \int z d z\right]_{z_{\mathrm{b}}}^{z_{\mathrm{t}}}\right. \\
& \left.-\int_{z_{\mathrm{b}}}^{z_{\mathrm{t}}}\left(\int z d z\right) A_{\mathrm{SAT}}^{\prime}(z) d z\right]
\end{aligned}
$$

SYRSOC inverts Eq. (2) with respect to $D$ between the cloud base $\left(z_{\mathrm{b}}\right)$ and the cloud top $\left(z_{\mathrm{t}}\right)$ at each time step. $D$ accounts for the departure of the calculated LWP (right-hand side of Eq. 2) from the measured LWP (left-hand side of Eq. 2). The term $D$ is then a correction factor and accounts for the overestimation $(D<1)$ or underestimation $(D>1)$ of the integrated term $A_{\mathrm{SAT}} \cdot z$ with respect to the instrumental LWP.

\subsection{Level 2: CDNC}

The first microphysical variable retrieved by SYRSOC is the CDNC. The retrieval technique is based on the inherent link between the CDNC, the LIDAR extinction, $\sigma$, and the LWC outlined by Boers and colleagues in 1994, 2000 and 2006. We do not repeat here their calculations but only show the result of their analysis assuming the DSD to be adequately described by a Gamma distribution. Then the number of droplets $N$ at time $t$ and height $z$ above the cloud base $\left(z_{\mathrm{b}}\right)$ can be written as

$N(z)=\left\{\frac{\sigma(z)}{\pi^{1 / 3} Q k_{2}\left(\frac{4}{3} \rho_{\mathrm{w}}\right)^{-2 / 3} f(z)^{2 / 3} A_{\mathrm{ad}}^{2 / 3}\left(z-z_{\mathrm{b}}\right)^{2 / 3}}\right\}^{3}$

Here, $\rho_{\mathrm{w}}$ is the density of liquid water; $\sigma$ is the extinction coefficient; $Q$ is the extinction efficiency, which, in Mie approximation for Gamma-type water DSD and for a LIDAR wavelength of $1.06 \mu \mathrm{m}$, can be assumed constant, $Q \approx 2$ (Pinnick et al., 1983). The coefficient $k_{2}$ is function of the size parameter $\alpha$ of the Gamma distribution which describes the droplet spectrum. It is convenient to adopt the already known and extensively used Gamma distribution (Boers and Mitchell, 1994) to describe the size droplet spectrum for cases of liquid water clouds:

$n(r, z)=a(z) r(z)^{\alpha} \exp (-b(z) r(z))$

where $n$ is the droplet concentration density, $r$ is the radius of the droplets, $b(z)$ is called rate parameter and $a(z)$ is a function of the rate parameter and the Gamma function $(\Gamma(\alpha))$. The values of $\alpha$ depend on the air mass in which the cloud forms and can be parameterized by $\alpha=3$ and $\alpha=7$ in

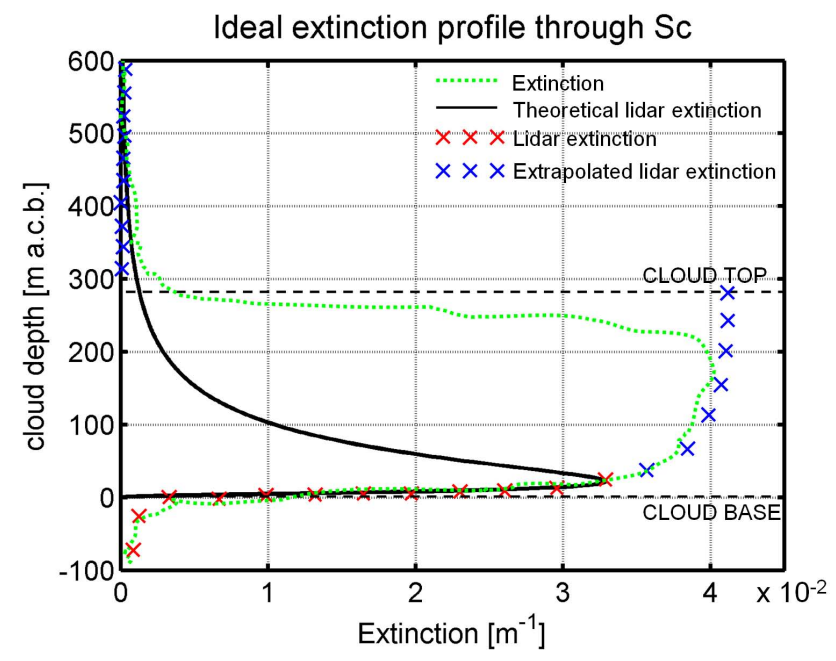

Fig. 3. Black solid: log-normal ideal extinction profile through the cloud layer; red crosses: lidar-retrieved $\sigma$-points; green dashed: not fully attenuated extinction profile; blue crosses: power-law extrapolated $\sigma$-points; black dashed: cloud top and base levels.

marine and continental air, respectively (Miles et al., 2000; Goncalves et al., 2008). Depending on the vertical resolution of the extinction profile a limited number of $\sigma$-points (normally 10-15 points with $15-\mathrm{m}$ resolution) can be used to regress in a least-squares sense Eq. (3) to each extinction profile with $N$ as a free parameter. The model used to fit Eq. (3) is a power-law of type $y=C x^{b}$ where the independent variable $x$ is the relative height above the cloud base multiplied by $f(z)$ while $N$ is kept constant and embedded into the constant $C$. Figure 3 shows a hypothetical case of cloud layer extending $\sim 300 \mathrm{~m}$ above the cloud base. Four representations of extinction profiles are pictured: a LIDAR-retrieved $\sigma$-profile in the not-fully-attenuated region (red crosses), the theoretical LIDAR profile through the cloud layer (black solid), the not-attenuated extinction profile through the entire cloud layer (green dashed) as it could be retrieved by measurements made by particulate spectrometers carried aloft by tethered balloons (e.g. Lindberg et al., 1984) and the extrapolated $\sigma$-points as a result of the $y=C x^{b}$ curve-fit (blues crosses). The error related to the curve-fit to retrieve $N$ represents a major source of uncertainty, i.e. the extrapolated $\sigma$ points can deviate from the not-attenuated extinction profile through the cloud (difference between the green curve and blue crosses in Fig. 3). Differences of both signs can lead to either underestimated or overestimated values of $N$ producing an uncertainty which propagates to the other microphysical variables (see Sect. 5). Once calculated, the CDNC is assumed to remain constant with height in the region of full attenuation (using the mean value of blue crosses in Fig. 3). 


\subsection{Level 3: $r_{\text {eff }}$}

The second microphysical variable calculated by SYRSOC is the $r_{\text {eff }}$, defined as the ratio of the third to the second moment of the DSD (Frisch et al., 1998, 2000). Fox and Illingworth (1997) found an almost one-to-one relation between the RADAR reflectivity factor and $r_{\text {eff }}$. Based on this relation, $r_{\text {eff }}$ can be expressed as the sixth root of the ratio between the detected RADAR reflectivity and the retrieved CDNC. Following Brandau's calculations (2010) $r_{\text {eff }}$ can be written as:

$$
\begin{aligned}
r_{\mathrm{eff}}(z) & =\frac{\left\langle r(z)^{3}\right\rangle}{\left\langle r(z)^{2}\right\rangle}=k_{2}^{-1} f(z)^{1 / 3}\left\langle r(z)^{3}\right\rangle^{1 / 3}, \\
k_{2} & =\frac{\alpha^{\frac{1}{3}}(\alpha+1)^{\frac{1}{3}}}{(\alpha+2)^{\frac{2}{3}}}
\end{aligned}
$$

Here, the term $k_{2}$ is the same as in Eq. (3) and expresses the constant relation between the second and the third moment of the DSD. In case of Rayleigh approximation, the relation between $\left\langle r(z)^{6}\right\rangle$ and the RADAR reflectivity factor $Z\left[\mathrm{~mm}^{6} \mathrm{~m}^{-3}\right]$ is:

$\left\langle r(z)^{6}\right\rangle=\frac{Z(z)}{64 N(z)}$

Using the relation between the third and the sixth moment of the DSD (Atlas, 1954; Frisch et al., 1998):

$\left\langle r(z)^{3}\right\rangle=\left[\frac{\left\langle r(z)^{6}\right\rangle}{k_{6} f(z)^{2}}\right]^{1 / 2}, \quad k_{6}=\frac{(\alpha+3)(\alpha+4)(\alpha+5)}{\alpha(\alpha+1)(\alpha+2)}$

The coefficient $k_{6}$ depends also on the shape parameter $\alpha$ and expresses the constant relation between the sixth and the third moment of the DSD.

Then, using Eqs. (5) and (6) and by combining with Eq. (4), $r_{\text {eff }}$ can be written as:

$r_{\mathrm{eff}}(z)=k_{2}^{-1} k_{6}^{-\frac{1}{6}}\left(\frac{Z(z)}{64 N(z)}\right)^{1 / 6}$

\subsection{Level 3: LWC}

The third microphysical variable calculated by SYRSOC is the LWC which can be retrieved, as shown in Eq. (1a), as a function of the third moment of the DSD and the retrieved CDNC. In the approximation of particles larger than the (LIDAR) wavelength, the extinction can be related to the second moment of the DSD by (Boers and Mitchell, 1994):

$\sigma(z)=2 \pi N(z)\left\langle r(z)^{2}\right\rangle$

By combination of Eqs. (1a), (7) and (8) the LWC $\left[\mathrm{g} \mathrm{m}^{-3}\right.$ ] can be expressed in the form:

$\operatorname{LWC}(z)=\frac{1}{3} \rho_{\mathrm{W}} N(z)^{-\frac{1}{6}} k_{2}^{-1} k_{6}^{-\frac{1}{6}} Z(z)^{\frac{1}{6}} \sigma(z)$

\section{Results}

All microphysical variables are calculated by SYRSOC and shown in two-panel figures for the continental and the marine cases in the following sub-sections. A table at the end of Sect. 5 summarizes the comparison of the retrieved microphysics with the related uncertainty for the two cases.

\subsection{Subadiabatic function $f(z)$}

Subadiabatic conditions are mainly determined by entrainment of dry air at the top of the cloud and by mixing of diluted and undiluted air at the cloud base due to updrafts and downdrafts and to precipitation processes. The entrainment at the cloud top enhances the droplets evaporation thus decreasing their average radius; the CDNC at the cloud top can also be depleted by the entrainment. By solving Eqs. (1-2) the subadiabatic function $f(z)$ can be determined and displayed as in Fig. 4 for the case study 28 May 2008 (top panel) and the case 10 December 2010 (bottom panel). For the continental case, the layer-averaged departure function $\bar{f}$ (at the bottom of each panel) shows little variations throughout the duration of the Sc with overall values remaining slightly below 0.1. In the vertical direction, $f(z)$ decreases with height through the cloud as $A_{\mathrm{SAT}}$ becomes smaller compared to $A_{\mathrm{ad}}$. During the first part of the Sc (21:30-22:30 UTC) $f(z)$ is in the range $0.05-0.08(\bar{f}=0.063)$; correspondingly to the increased cloud thickness during 22:30-24:00 UTC $f(z)$ increases showing values between 0.06 and $0.13(\bar{f}=0.085)$.

The bottom panel shows the values of $f(z)$ for the marine case: the Sc can be divided into three parts, from 11:00 to $12: 45 \mathrm{UTC}$, from $12: 45$ to $13: 45 \mathrm{UTC}$ and from $13: 45$ to 16:00 UTC. The three intervals correspond to the periods over which the cloud is more homogeneous. The overall value of $f(z)$ during the entire event is higher than in the continental case, mainly due to the increased cloud thickness and the reduced entrainment in the inner part of the cloud. During the first and third parts $f(z)$ ranges between 0.1 and 0.4 $(\bar{f}=0.24)$ and 0.1 and $0.3(\bar{f}=0.2)$, respectively. During the central part $(\bar{f}=0.09)$ the cloud most likely undergoes significant entrainment and mixing with free-tropospheric air leading to more subadiabatic conditions compared to the other cloud parts. Both $A_{\mathrm{ad}}$ and $A_{\mathrm{SAT}}$ are higher compared to the continental case showing that the rate of growth of the adiabatic LWC through the cloud is larger in marine than in continental air. The relative and absolute humidity retrieved by the MWR showed for both cases that the entrainment can reduce the level of supersaturation and initiate the evaporation of cloud droplets while decreasing the amount of liquid water especially at the cloud top. 

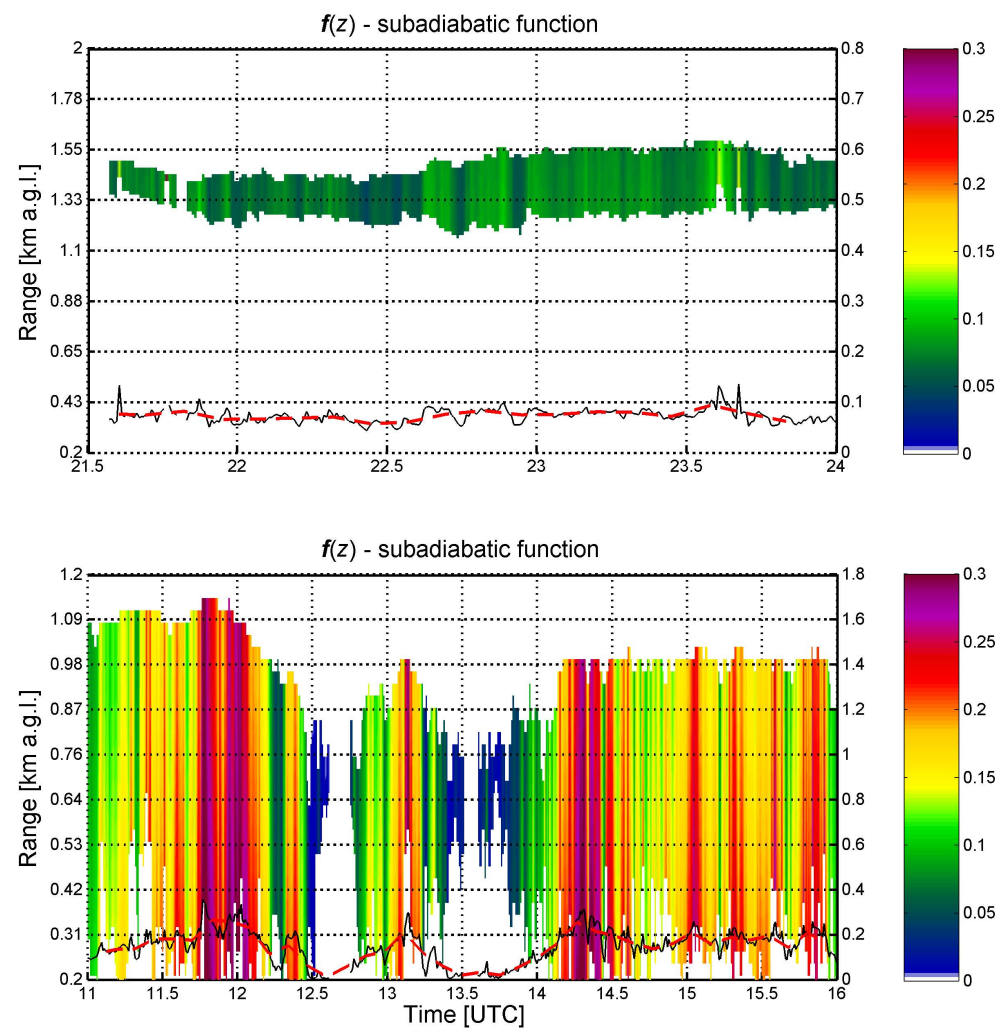

Fig. 4. Continental (top) and marine (bottom) case: subadiabatic function, $f(z)$. Black solid lines at the bottom of top and bottom panels (right-hand y-axis) are the layer-averaged and 7.5-min averaged $f(z)$.

\subsection{CDNC}

The results shown in Fig. 5 are obtained using Eq. (3). Continental case: the mean CDNC is $382 \mathrm{~cm}^{-3}$, the median is $180 \mathrm{~cm}^{-3}$ and the 10th to 90th-percentile range is $9.4-$ $842.2 \mathrm{~cm}^{-3}$. The layer-averaged CDNC (black-solid line) has values mainly between 0 and 800 droplets $\mathrm{cm}^{-3}$ with peaks at $1200 \mathrm{~cm}^{-3}$. The layer- and 7.5 -min averaged CDNC (red-dashed line) remains around 500 droplets $\mathrm{cm}^{-3}$ during the period when the cloud is thicker (22:45-23:45 UTC). In continental Sc clouds the mean CDNC normally ranges between 300 and $400 \mathrm{~cm}^{-3}$ (Miles et al., 2000) leading to small $r_{\text {eff }}$ and brighter clouds. The RADAR reflectivity $Z$ depends on the sixth moment of the droplet size distribution, causing continental clouds with high CDNC and small $r_{\text {eff }}$ to be associated with small $Z$-values. This is confirmed by the low mean reflectivity factor $\bar{Z}=-44 \mathrm{dBZ}$ and the low mean $\overline{\mathrm{LWP}}=40 \mathrm{~g} \mathrm{~m}^{-2}$. Drizzle is not present during the period of observation indicating that the coalescence process through the cloud layer is not as efficient as to generate droplets large enough to fall out of the cloud. The layer-averaged CDNC show significant variability at the temporal resolution of 0.5 min while almost all variability disappears reducing the temporal resolution to $7.5 \mathrm{~min}$. The different temporal resolution allows to study the effect of averaging on the indirectly re- trieved cloud dynamics. The updraft and downdraft velocity can be derived by the cloud RADAR Doppler velocity that for the continental and the marine cases is on the order of $|0.5| \mathrm{m} \mathrm{s}^{-1}$ and $\sim|1| \mathrm{m} \mathrm{s}^{-1}$, respectively. Because the mean cloud depth where the cloud is thicker is $\sim 0.5 \mathrm{~km}$ and $\sim 1 \mathrm{~km}$ for the continental and marine clouds, this leads to $\sim 15 \mathrm{~min}$ for both cases to have the full ascent/descent of an air parcel through the cloud depth. The 7.5-min temporal resolution allows then to observe (where the process can be detected) the cloud dynamics while reducing significantly the noise. The effect of averaging will become even clearer when the retrieved CDNC will be compared to the measured CCN at 10min resolution (Sect. 4.2.1). The number of droplets remains substantially constant through the central and upper part of the layer with a net increase of CDNC occurring only in the bottom part of the cloud and leading to an average total vertical variability of about $10 \%$ (CDNC variability only corresponds to the not-fully-attenuated region, i.e. red crosses in Fig. 3). Conversely, the temporal variability of CDNC is significant (10th to 90th-percentile range of variability corresponds to the $218 \%$ of the mean value) and is partially related to the updraft and downdraft cycle within the cloud.

Marine case: Fig. $5 \mathrm{~b}$ shows the clean marine stratocumulus with mean CDNC as low as $25 \mathrm{~cm}^{-3}$, the median is $10.5 \mathrm{~cm}^{-3}$ and the 10th to 90th-percentile range is 

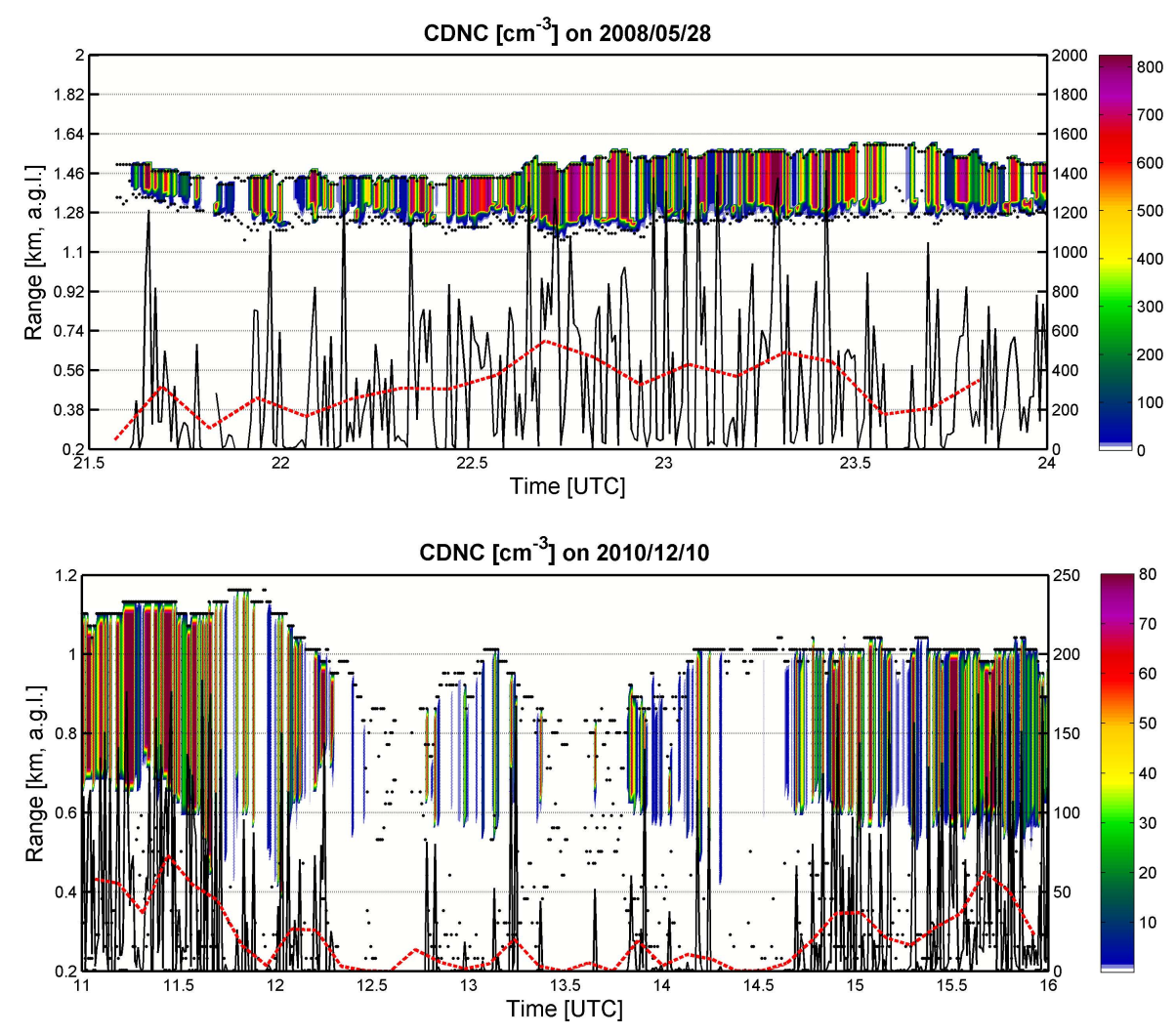

Fig. 5. Continental (top) and marine (bottom) case: time-height cross section of the CDNC $\left[\mathrm{cm}^{-3}\right]$. Layer-averaged black and red curves at each panel's bottom (right y-scale in $\left[\mathrm{cm}^{-3}\right]$ ) have 0.5 -min and 7.5 -min temporal resolution, respectively.

$1.5-69 \mathrm{~cm}^{-3}$. The increased (compared to the continental) cloud vertical extent which includes the area with the drizzle leads to the mean cloud thickness of $687 \mathrm{~m}$ ( $246 \mathrm{~m}$ for the polluted). The lowest part of the cloud is the area where only the drizzle drops with very few counts $\left(\sim 1 \mathrm{~cm}^{-3}\right)$ are present; the depletion of CDNC in correspondence to the drizzle affects the vertical variability which is as high as $88 \%$ (but it drops to $8 \%$ if the drizzle region is not considered). The temporal variability is as well considerably high and higher than the continental case, (10th to 90th-percentile range of variability corresponds to the $270 \%$ of the mean value). The small number of droplets combined with the presence of drizzle is in agreement with the efficient production of large droplets, also supported by the high mean reflectivity factor $\bar{Z}=-8 \mathrm{dBZ}$.

\subsubsection{CDNC-CCN}

For boundary-layer clouds like the presented continental and marine cases it is possible to perform an evaluation of the retrieved CDNC by comparing with in-situ measured $\mathrm{CCN}$, notwithstanding the fact that such evaluation is difficult in its own right. In fact, with no in-situ CDNC available, we compared the SYRSOC-retrieved CDNC with the surfacemeasured $\mathrm{CCN}\left(N_{\mathrm{CCN}}\right)$. The comparison has been per- formed based on the fact that the boundary layer was wellmixed and that the surface $\mathrm{CCN}$ should reproduce well the CCN concentrations at cloud base (O'Dowd et al., 1992, 1999). The CDNC- $N_{\mathrm{CCN}}$ comparison provides a qualitative estimation of the supersaturation (ss) achieved within the cloud. Each ss scan lasts $5 \mathrm{~min}$ and, depending on the case, the selected ss values ranged from $0.1-0.25-0.5-0.75-1 \%$. The outcome of the comparison is shown at 10-min of temporal resolution in Fig. 6 for the continental (left) and the marine (right) case: for both cases the CDNC closely match the $N_{\mathrm{CCN}}$ at one or more ss values. Whilst for the continental case the comparison clearly suggests that the level of ss within the cloud does not exceed $0.1 \%$ (i.e. $100.1 \%$ ), for the marine case the CDNC curve lays between $0.1 \%$ and $0.75 \%$ ss. The average ss within the continental cloud is lower than the marine cloud suggesting a larger entrainment for the continental case. The lower ss for the continental case can be explained partly by the cloud dynamics and partly by the larger $N_{\mathrm{CCN}}$ that tends to reduce peak ss (Hudson et al., 2010). It should also be noticed that for the marine cloud the derived ss is influenced by droplet removal due to entrainment and coalescence scavenging (drizzle formation). As a consequence, the derived ss is an underestimate of the peak ss reached during the activation phase. The 10-min resolution suggests different reasons for the CDNC variability 

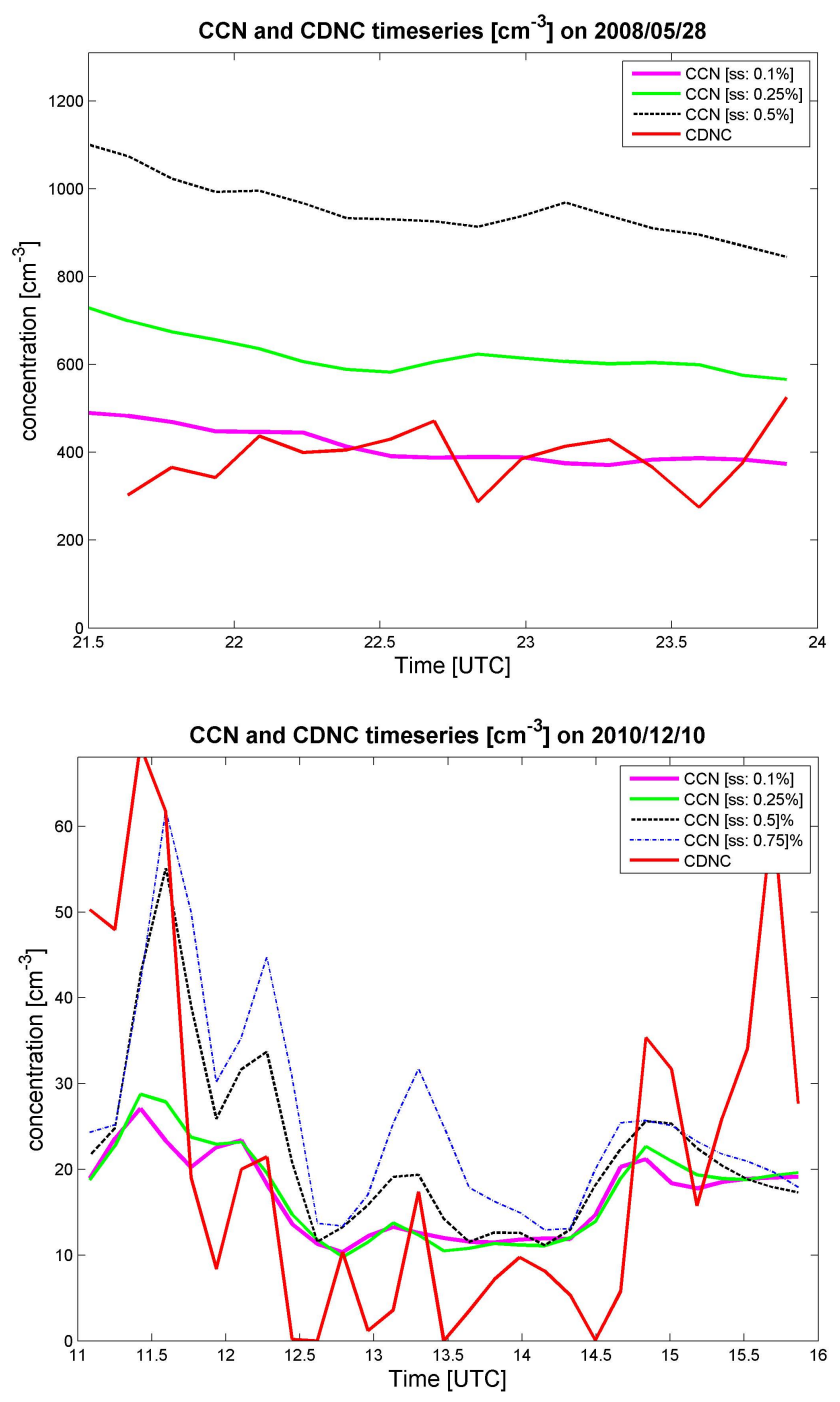

Fig. 6. Continental (left) and marine (right) case: comparison between $\mathrm{CDNC}$ and $\mathrm{CCN}$ at supersaturation levels of $0.1 \%-0.25 \%-$ $0.5 \%-0.75 \%$. Temporal resolution is $10 \mathrm{~min}$.

during the retrieval time in the two cases: while for the continental case the $0.1 \% \mathrm{ss} N_{\mathrm{CCN}}$ is very stable, for the marine case the $N_{\mathrm{CCN}}$ at all ss-levels vary up to $300 \%$ of their mean value. The CDNC follow the $N_{\mathrm{CCN}}$ changes in the marine case which suggests that the variability does not come from the cloud dynamics. On the other hand, for the continental case, the CDNC show 30-min timescale variability that could depend primarily on the updraft and downdraft cycle.

\section{$4.3 \quad r_{\text {eff }}$}

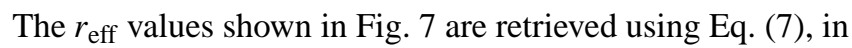
the right-hand frames are shown examples of near-adiabatic and sub-adiabatic $r_{\text {eff }}$ mean profiles corresponding to relative maximum and minimum of $f(z)$, respectively. Continental case: since $r_{\text {eff }}$ depends directly on the RADAR reflectivity factor, in drizzle-free conditions the lowest part of the cloud where the smallest droplets are confined is often not detected by the cloud RADAR. This happens normally with droplets $r_{\text {eff }}$ smaller than $2 \mu \mathrm{m}$ which are found at the cloud base. When, like for this case, the entrainment at the top of the cloud is significant the cloud droplets can partially evaporate due to the lower relative humidity leading to smaller droplets. For this reason in the top panel of Fig. 7 the $r_{\text {eff }}$ data are missing immediately below and above the cloud top and base, respectively. The mean $r_{\text {eff }}$ is $4.3 \mu \mathrm{m}$, the median is $3.95 \mu \mathrm{m}$ and the 10th to 90th-percentile range is $2.91-6.45 \mu \mathrm{m}$. The small mean (and median) effective radius is in agreement with the low value of $\bar{Z}$ discussed in the previous section. Moreover, the low mean LWP $\left(\overline{\mathrm{LWP}}=40 \mathrm{~g} \mathrm{~m}^{-2}\right)$ suggests that not too much water vapour was available for condensation onto the $\mathrm{CCN}$, thus limiting their condensational growth into large $r_{\text {eff. }}$ The nearly-adiabatic $r_{\text {eff }}$ profile shows a constant increase in radius from cloud base to cloud top, on the other hand the sub-adiabatic $r_{\text {eff }}$ profile has more irregular vertical trend with a peak at the cloud base probably due to drizzle onset.

Marine case: the mean $r_{\text {eff }}$ value is $28.4 \mu \mathrm{m}$, the median is 23.6 and the 10th to 90th-percentile range is $11.2-42.7 \mu \mathrm{m}$. The very large mean $r_{\text {eff }}$ results from including the drizzle $r_{\text {eff }}$ in the average, and it is then not representative of the CDNC-weighted $r_{\text {eff }}$ distribution. The mean number of drizzle drops is, as stated above, $\bar{N}=1 \mathrm{~cm}^{-3}$ then a correct measure of the modal $r_{\text {eff }}$ must come from CDNC-weighted analysis of the effective DSD. Differently from the continental case, both the near-adiabatic and subadiabatic profiles have a very large peak $\left(r_{\text {eff }}>40 \mu \mathrm{m}\right)$ corresponding to fully developed drizzle. Compared to the subadiabatic, with approximately $19-\mu \mathrm{m}$ profile through the cloud, the near-adiabatic profile shows much larger radii through the actual cloud $\left(40>r_{\text {eff }}>80 \mu \mathrm{m}\right)$. The trend decreases from base to top of the cloud suggesting that coalescence dominates the $r_{\text {eff }}$ during that time interval.

\subsubsection{MODIS effective radius}

A comparison between SYRSOC-retrieved and satelliteretrieved $r_{\text {eff }}$ has been performed for the continental and marine stratocumuli. L2 $r_{\text {eff }}$ products from TERRA and AQUA Moderate-resolution Imaging Spectroradiometer (MODIS) satellites have been extracted for the overpasses containing the Mace Head station $\left(53.33^{\circ} \mathrm{N}, 9.9^{\circ} \mathrm{W}\right)$. For the continental case (28 May 2008) no overpass was available during the retrieval period 21:30-24:00 UTC; the (temporally) closest overpass was then selected at 12:20 UTC when a similar cloud field was present over Mace Head. The 12:20 UTC TERRA-overpass can be used as qualitative indication of the $r_{\text {eff }}$ a few hours later since the air mass did not change and the number of $\mathrm{CCN}$ remained fairly constant during the period 12:00-24:00 UTC. Figure 8 shows the two overpasses for the continental (left) and marine (right) case with 

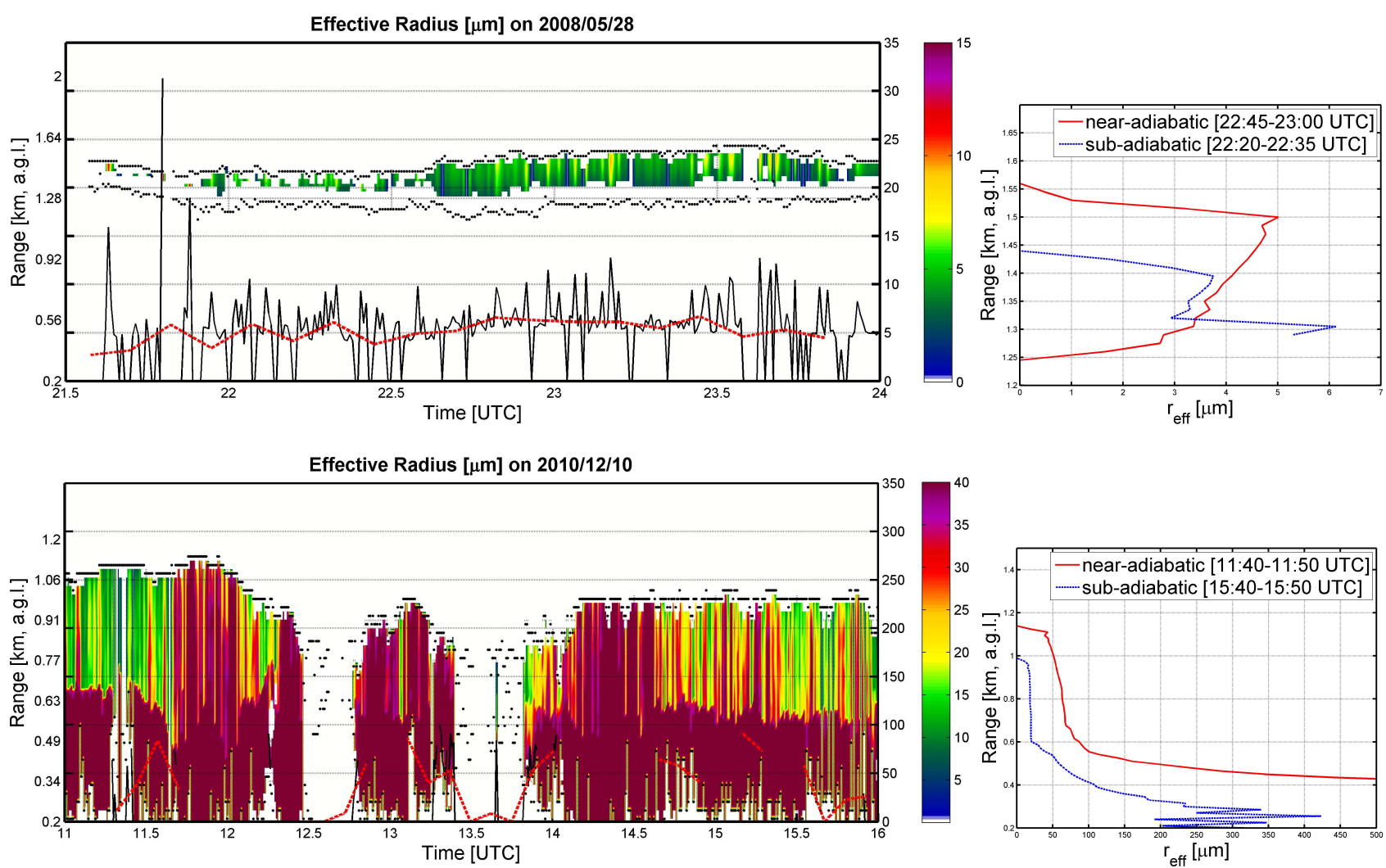

Fig. 7. Continental (top) and marine (bottom) case: time-height cross section of the effective radius $r_{\text {eff }}$ [ $\mu m$ ]. Layer-averaged black and red curves at each panel's bottom (right y-scale in $[\mu \mathrm{m}]$ ) have 0.5 -min and 7.5-min temporal resolution, respectively. Profiles in highlighted frames show near-adiabatic (solid red) and sub-adiabatic (dashed blue) $r_{\text {eff }}$ profiles corresponding to, respectively, maxima and minima of the departure function $f(z)$.

highlighted $0.6 \times 0.6$-degrees box embedding the Mace Head geographical position. The two box-averaged $r_{\text {eff }}$ values are compared with the mean cloud top $r_{\text {eff }}$ for the continental and marine cases. The 14:00-14:30 UTC time interval has been selected to compare SYRSOC and MODIS $r_{\text {eff. In daytime, effective radius from MODIS is calculated }}$ from the combination of reflectances in two channels in the very-near infrared, and in the near-infrared. Therefore, the MODIS measurement of $r_{\text {eff }}$ comes from the cloud emitting region in the very-near and near-infrared (Platnick, 2000). If it is assumed that the dominant region for emission in this band is similar to the region where the cloud is optically thick, then, for the downward observation, this would be the top couple of hundred metres of a liquid layer. The MODIS-retrieved $r_{\text {eff }}$ would then be more representative of the cloud upper layer and should then be compared with the SYRSOC-retrieved mean $r_{\text {eff }}$ from the upper 100-m cloud layer. For the continental case, the satellite-retrieved $r_{\text {eff }}$ was $7 \mu \mathrm{m}$ to be compared with the upper layer SYRSOC-retrieved $r_{\text {eff }}$ which was $6.2 \mu \mathrm{m}$. The SYRSOC-retrieved $r_{\text {eff }}$ results from an average over the period when the cloud was optically thicker (22:40-24:00 UTC). For the marine case, the satellite-retrieved $r_{\text {eff }}$ was $16.2 \mu \mathrm{m}$ and $17 \mu \mathrm{m}$ was the upper layer SYRSOC-retrieved $r_{\text {eff }}$ during 14:00-14:30 UTC.

\subsubsection{Effective DSD analysis}

The vertical profiles of $r_{\text {eff }}$ show very low degree of variability in the drizzle region and higher within the cloud. The $r_{\text {eff }}$ vertical variability can be expressed as the ratio of the standard deviation to the mean $r_{\text {eff }}$ where the variability gives information on the droplet spectral dispersion. Both, the CDNC-weighted $r_{\text {eff }}$ modal value and relative dispersion are shown in Fig. 9 for both the continental and the marine case. Figure 9 shows the relative dispersion index ( $\mathrm{Lu}$ and Seinfeld, 2006; Lu et al., 2009), the $r_{\text {eff }}$ Frequency Distribution (RFD) normalized by the total cloud CDNC and the relation between the available cloud water (in terms of LWP) and the activated particles. The index $d$ is the ratio of the standard deviation (droplet spectral width) to the mean $r_{\text {eff }}$ of the cloud DSD:

$d=\sigma_{r_{\mathrm{eff}}} / \overline{r_{\mathrm{eff}}}$ 


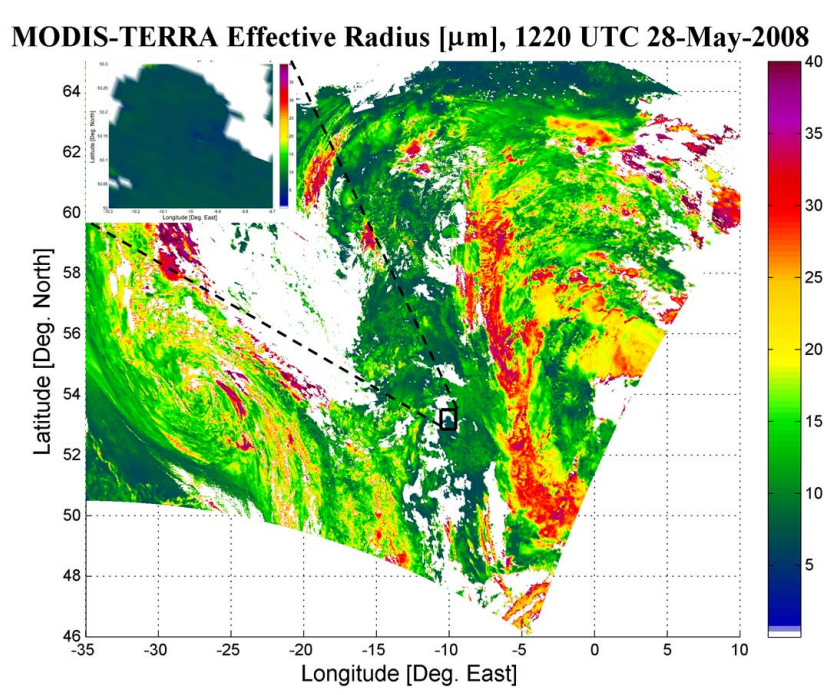

MODIS-AQUA Effective Radius $[\mu \mathrm{m}], 1420$ UTC 10-Dec-2010

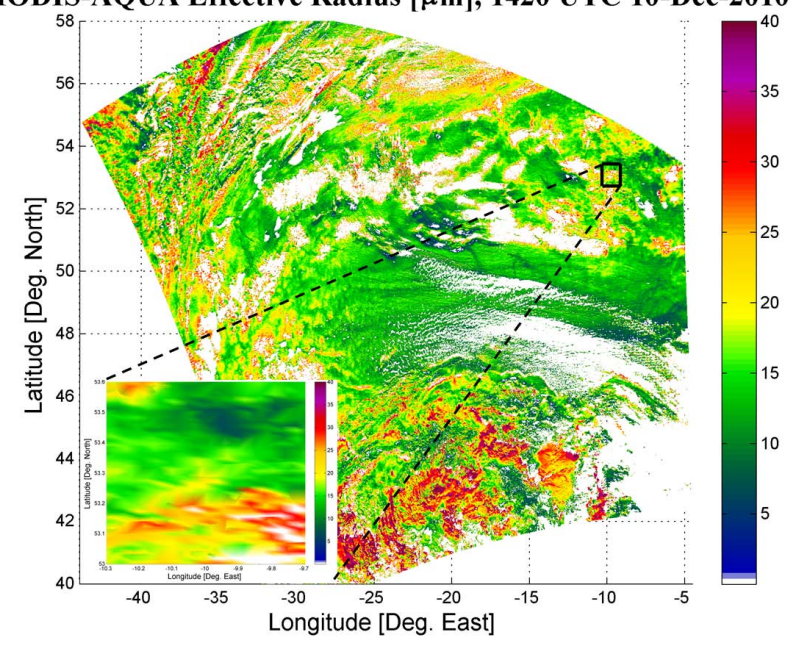

Fig. 8. MODIS-TERRA cloud effective radius from 12:20 UTC overpass on 28 May 2008 (left) and MODIS-AQUA cloud effective radius from 14:20 UTC overpass on 10 December 2010 (right). In enlarged frames are shown the $0.6 \times 0.6 \mathrm{deg}$ box containing Mace Head Station $\left(53.33^{\circ} \mathrm{N},-9.9^{\circ} \mathrm{E}\right)$.

Continental case: the left panel shows the relative dispersion index $d$ as function of the layer-averaged CDNC. The scatter diagram shows the relative dispersion decreasing with increasing CDNC, i.e. the spectral width of the droplet distribution become narrower when the number of particles increases. The middle panel shows the RFD versus the $r_{\text {eff }}$ between 0 and $30 \mu \mathrm{m}$. The RFD represents the CDNC-weighted $r_{\text {eff }}$ distribution and shows that the modal $r_{\text {eff }}\left(r_{\text {eff }}^{\mathrm{MOD}}=4.7 \mu \mathrm{m}\right)$ is almost in a $1: 1$ relation with $\overline{r_{\text {eff }}}$. The narrow RDF and the correspondence between modal and mean $r_{\text {eff }}$ is due to the drizzle-free conditions in which the continental Sc formed, more information will be added to the interpretation of this result after the analysis of the marine case. The right panel shows the Equivalent CDNC, i.e. the ratio between the activated particles and the total amount of liquid water in the cloud (CDNC/LWP). The ratio provides information on the efficiency to generate the CDNC. The relatively high mean Equivalent CDNC $\left(9.94 \mathrm{~cm}^{-3} \mathrm{~g}^{-1} \mathrm{~m}^{2}\right.$, dashed horizontal line) gives an alternative representation of the continental conditions in which the cloud formed.

Marine case: in contrast to the continental case, the relative dispersion $d$ does not show correlation with the averaged CDNC. In correspondence with the drizzle the relative dispersion is high suggesting a broad spectral width. The dispersion remains uncorrelated with the CDNC also when the CDNC increases. A reason for that is the low CDNC in the cloud, i.e. the relative dispersion normally starts decreasing for $\mathrm{CDNC}>100 \mathrm{~cm}^{-3}$ (e.g. continental case), but for the studied marine case the CDNC do not exceed the value of $80 \mathrm{~cm}^{-3}$ unless by a negligible fraction of occurrences. In the middle panel it is shown a much broader RDF than the continental case with occurrences over the entire $0-30 \mu \mathrm{m}$ spectrum and modal $r_{\mathrm{eff}}^{\mathrm{MOD}}=12 \mu \mathrm{m}$. In contrast to the continental case, the $\overline{r_{\text {eff }}}(28.4 \mu \mathrm{m})$ does not correspond to $r_{\mathrm{eff}}^{\mathrm{MOD}}$ being twice its value. The departure is due to the marginal (in terms of occurrences) contribution of drizzle to the cloud $r_{\text {eff. }}$ The right panel shows the Equivalent CDNC which, especially when compared with the continental case, well describes the marine characteristic of the studied Sc with very low equivalent CDNC $\left(0.16 \mathrm{~cm}^{-3} \mathrm{~g}^{-1} \mathrm{~m}^{2}\right)$.

\subsection{LWC}

The results shown in Fig. 10 are obtained using Eq. (9). Continental case: the mean $\mathrm{LWC}$ is $0.19 \mathrm{~g} \mathrm{~m}^{-3}$, the median is $0.15 \mathrm{~g} \mathrm{~m}^{-3}$ and the 10th to 90th-percentile range is $0.11-$ $0.22 \mathrm{~g} \mathrm{~m}^{-3}$. In purely adiabatic conditions the LWC would increase linearly with the slope $A_{\text {ad }}$, leading to higher content of liquid water at the cloud top than in subadiabatic conditions (slope $A_{\mathrm{SAT}}$ ). In agreement with the calculated values of $f(z)$, the vertical LWC profiles are subadiabatic during most of the Sc with only short near-adiabatic periods. Top panel of Fig. 10 shows in highlighted frames an example of near-adiabatic and sub-adiabatic LWC mean profiles corresponding to relative maximum and minimum of $f(z)$, respectively. Equation (9) expresses the LWC in terms of both the LIDAR extinction $\sigma$ and the RADAR reflectivity factor $Z$, so that the LWC depends on the optical cloud properties at different wavelengths. The dependence on both Mie and Rayleigh scattering ensures a correct representation of the contribution from both small and large droplets to the LWC.

Marine case: the mean LWC is $0.16 \mathrm{~g} \mathrm{~m}^{-3}$, the median is $0.13 \mathrm{~g} \mathrm{~m}^{-3}$ and the 10th to 90th-percentile range is $0.01-$ $0.38 \mathrm{~g} \mathrm{~m}^{-3}$. Compared to the continental case the mean value is smaller due to the small contribution of drizzle to the total amount of liquid water. Compared to the continental case, the larger cloud depth over which the rising air parcel can grow in liquid water determines a larger peak LWC $\left(0.37 \mathrm{~g} \mathrm{~m}^{-3}\right.$ for the continental and $1.25 \mathrm{~g} \mathrm{~m}^{-3}$ 

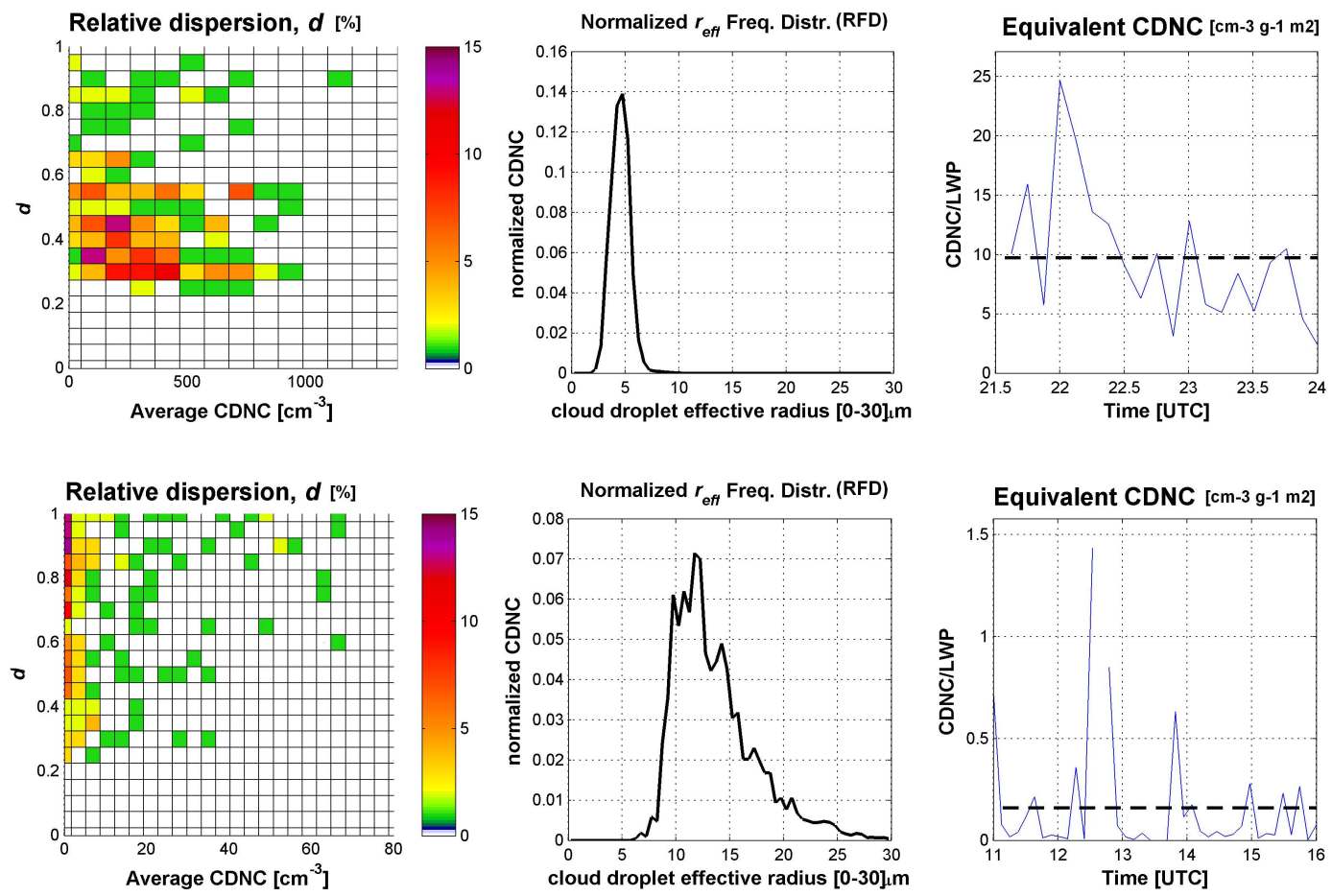

Fig. 9. Continental (top) and marine (bottom) case: relative dispersion index $d$ (\%, left); normalized $r_{\text {eff }}$ Frequency Distribution (RDF) versus droplet $r_{\text {eff }}$ between 0 and $30 \mu \mathrm{m}$ (middle); right panel: equivalent $\mathrm{CDNC}\left(\mathrm{cm}^{-3} \mathrm{~g}^{-1} \mathrm{~m}^{2}\right.$, right).

for the marine case). The larger degree of LWC variability is then responsible for the larger standard deviation $\left(\sigma_{\text {marine }} / \sigma_{\text {continental }}=400 \%\right)$. Also the overall larger values of $f(z)$ suggests a more efficient LWC growth for the marine case than for the continental. The LWC is indeed showing near-adiabatic growth (bottom panel Fig. 10) and local peaks in correspondence to the $f(z)$ local maxima (11:45-12:15 and 14:10-14:30 UTC). Conversely, during the time intervals when $f(z)$ shows a minimum the LWC peaks are located below the cloud top or even at mid-height between base and top.

\section{Error analysis and method sensitivity}

An error analysis and method sensitivity study is needed in order to asses SYRSOC. Three assumptions are made on the parameters in Eq. (3): (i) the extinction efficiency coefficient $Q$ at the wavelength $1.064 \mu \mathrm{m}$ is set to the constant value $Q=2$ (Bohren and Huffman, 1983); based on the calculations of Nussenzveig and Wiscombe (1980) and Pinnick and colleagues (1983), in the range of droplet radii $1-15 \mu \mathrm{m}$, the error introduced assuming constant $Q=2$, is $\Delta Q=-0.15(6.8 \%)$ at $1 \mu \mathrm{m}$ and $\Delta Q=+0.106(4.8 \%)$ at $15 \mu \mathrm{m}$. At larger radii the error rapidly drops below $1 \%$. (ii) The term $k_{2}$ depends on the exponent of the size parameter of the assumed Gamma distribution which describes the
DSD. The value of $\alpha$ depends on the type of air mass and can double from marine to continental air (Miles et al., 2000). Nonetheless, the method is sufficiently stable with respect to the variations of $\alpha$ : when $\alpha$ is in the range from 2 to 50 the relative changes in the retrieved $\mathrm{CDNC}$ are between 0 and $14 \%$. (iii) The correction term $D$ in Eq. (2) depends on the rate of change of condensable water during irreversible saturated pseudoadiabatic process $\left(A_{\mathrm{SAT}}\right)$ which in turn, depends on the radiometric cloud base temperature that has an accuracy of $\pm 0.7 \mathrm{~K}$ in the first $1000 \mathrm{~m}$. The overall uncertainty on the CDNC due to $A_{\mathrm{SAT}}$ can be regarded as systematic and its contribution as large as $6 \%$. Assuming all the terms in (i)(iii) as independent, the total contribution to the (maximum) uncertainty is the systematic error $\Delta N_{\text {syst }}=16.7 \%$.

The retrieval of the CDNC using Eq. (3) suffers the uncertainty introduced by the curve-fit regression of the extinction $\left(\Delta \sigma_{\mathrm{fit}}\right)$ in the region where the LIDAR signal is fully attenuated and by the assumption of the constant LIDAR ratio, $S$. Both errors propagate also to $r_{\text {eff }}$ and LWC determinations. The error introduced normalizing the LIDAR signal by $S\left(\Delta \sigma_{S}\right)$ propagates non-linearly first to the extinction's stable solution (Klett, 1981, Eq. 9) and then to the other microphysical variables. The total uncertainty related the calculation of the extinction can then be written as $\Delta \sigma=\sqrt{\left(\Delta \sigma_{\text {fit }}\right)^{2}+\left(\Delta \sigma_{S}\right)^{2}}$. The error $\Delta \sigma_{\text {fit }}$ is determined by the goodness-of-fit (GOF); the statistical parameters defining the GOF are the degrees of freedom, the coefficient of 

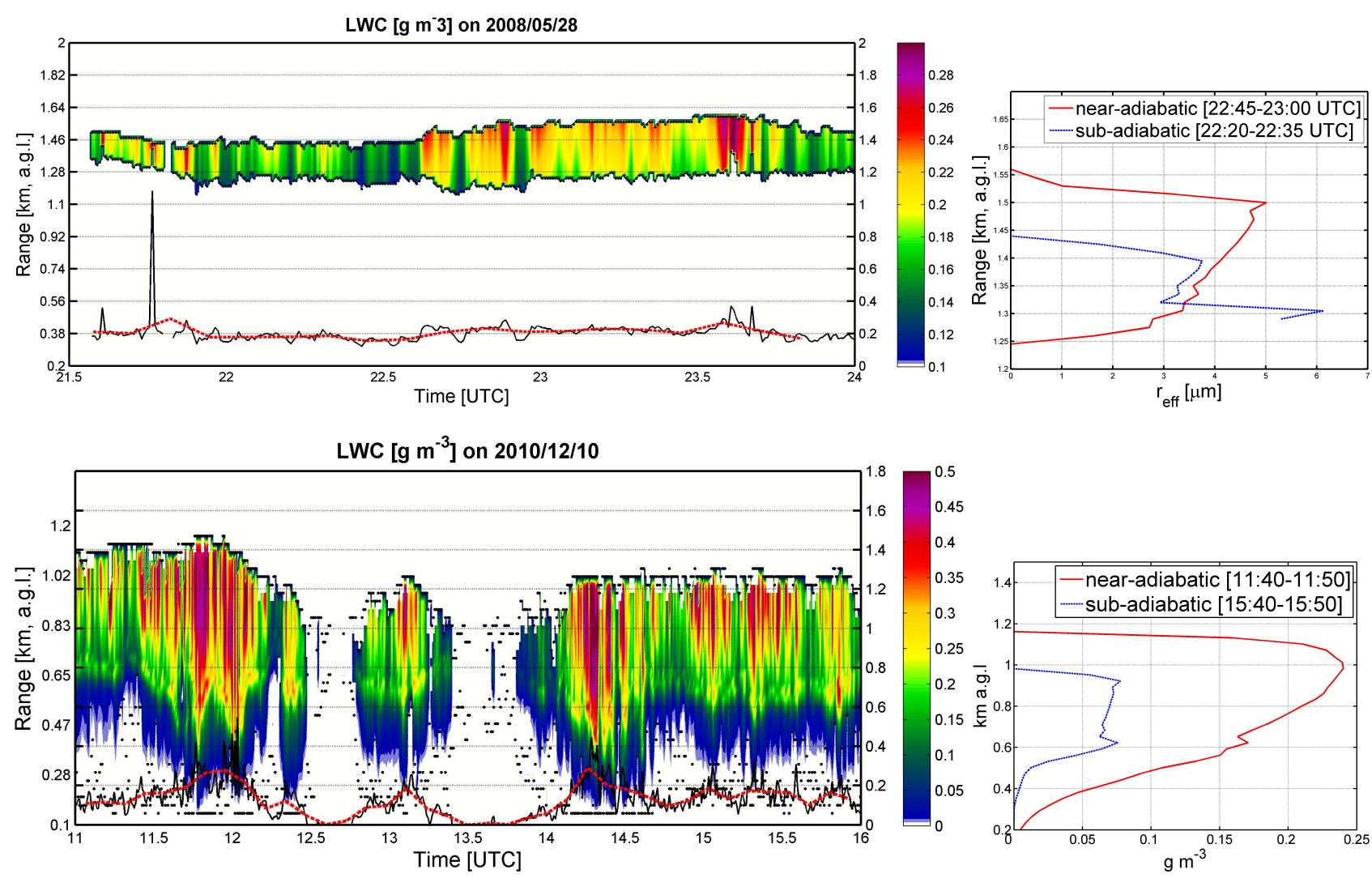

Fig. 10. Continental (top) and marine (bottom) case: time-height cross section of the liquid water content [ $\left.\mathrm{g} \mathrm{m}^{-3}\right]$. Layer-averaged black and red curves at each panel's bottom (right $\mathrm{y}$-scale in $\left[\mathrm{g} \mathrm{cm}^{-3}\right]$ ) have 0.5 -min and 7.5-min temporal resolution, respectively. Profiles in highlighted frames show near-adiabatic (red) and sub-adiabatic (blue) LWC profiles corresponding to, respectively, maxima and minima of the departure function $f(z)$.

determination and the root mean square error (RMSE) of the fit, but only the RMSE is retained to determine $\Delta \sigma_{\text {fit }}$.

The other source of uncertainty regards the departure function $f(z)$ calculated as the ratio of the product between $A_{\mathrm{SAT}}$ and the correction term $D$ to the adiabatic rate $A_{\text {add }}$. The retrieval of the term $D$ depends on the total (integrated) content of water through the cloud and on the cloud thickness. Inverting the integrated relation in Eq. (2) to obtain $D$ it is possible to shelve any dependence of $D$ on the vertical profile of the LWC excluding all a-priori assumption on the value of LWC. Nevertheless, the term $D$ depends on the MWRretrieved LWP which suffers a maximum $\pm 15 \mathrm{~g} \mathrm{~m}^{-2}$ error. The error on $D$ propagates then to the retrieval of $f(z)(\Delta f)$ through Eq. (1c) and finally to $N$ and the other microphysical variables through Eqs. (3), (7) and (9). The total uncertainty introduced by the two sources of statistical $(\Delta \sigma$ and $\Delta f)$ and systematic $\left(\Delta N_{\text {syst }}\right)$ error can be calculated by standard error propagation theory. Based on Eqs. (3), (10) and (12) the relative uncertainties for CDNC, $r_{\text {eff }}$ and LWC are, respectively:

$\Delta N=\left[\left(\frac{3 N}{\sigma} \Delta \sigma\right)^{2}+\left(\frac{3 N}{f} \Delta f\right)^{2}+\left(\Delta N_{\text {syst }}\right)^{2}\right]^{1 / 2}$
$\Delta r_{\text {eff }}=\frac{1}{6} \frac{r_{\text {eff }}}{N} \Delta N$

$\Delta \mathrm{LWC}=\left[\left(-\frac{1}{6} \frac{\mathrm{LWC}}{N} \Delta N\right)^{2}+\left(\frac{\mathrm{LWC}}{\sigma} \Delta \sigma\right)^{2}\right]^{1 / 2}$

The CDNC retrievals show the largest uncertainty for both the continental and the marine case. Both $\Delta \sigma$ and $\Delta f$ are assumed to have zero-covariance matrix when they propagate to the other variables. Figure 11 shows the total uncertainty (in \%) for the CDNC (upper panel), $r_{\text {eff }}$ (middle panel) and the LWC (bottom panel) for the continental (left) and the marine (right) case, respectively.

For both the continental and marine case, the CDNC is affected by the largest uncertainty with an average value of $42 \%$ (continental) and $49 \%$ (marine). The $r_{\text {eff }}$ has average uncertainty $20 \%$ (continental) and $19.1 \%$ (marine); the LWC uncertainty has values in between the two other retrievals, $18.4 \%$ (continental) and $25 \%$ (marine). The mean value, the uncertainty and statistical variability of each microphysical variable is summarized in Table 1 for the continental and marine case. For each variable the table shows 

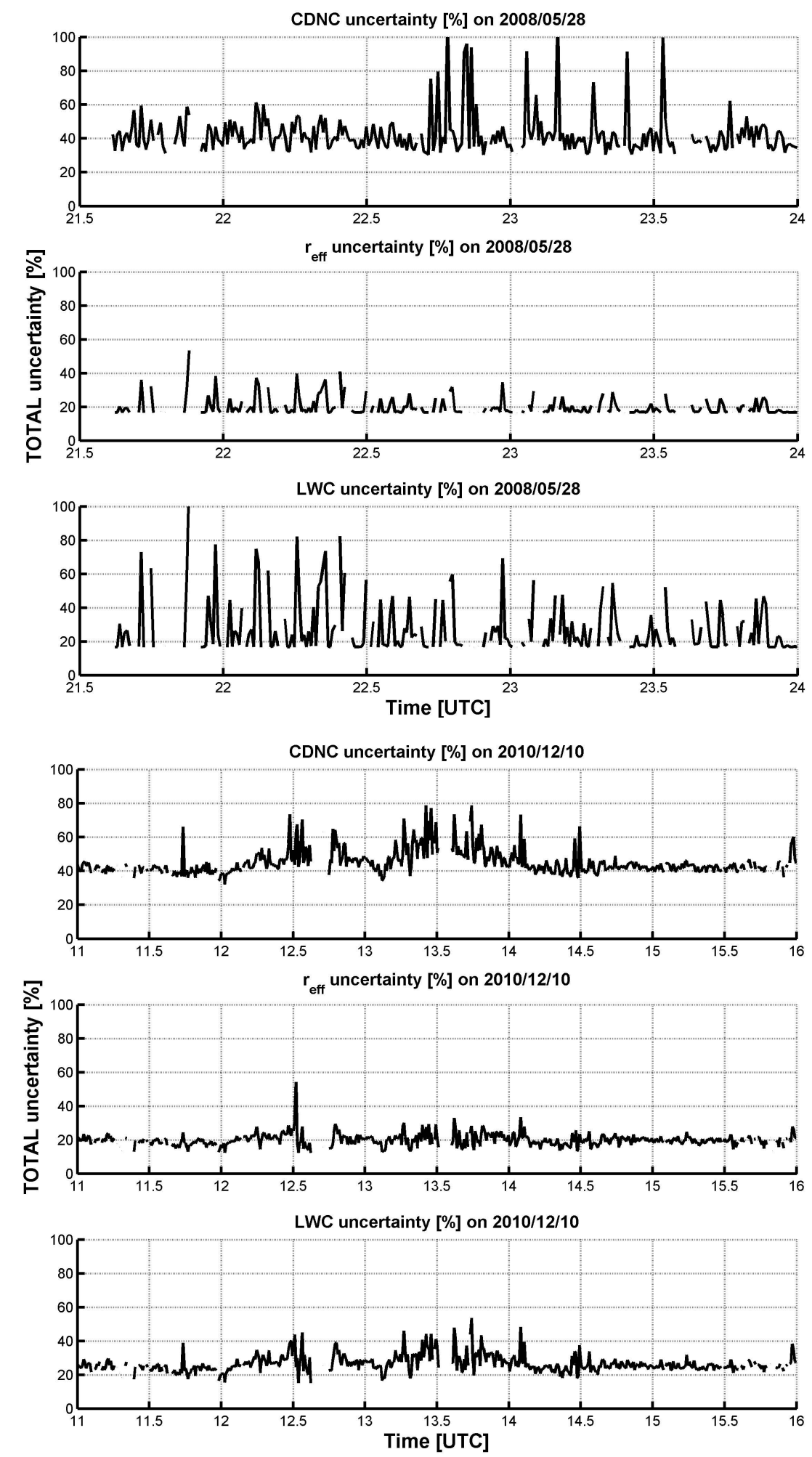

Fig. 11. Uncertainty [\%] for the CDNC (upper panel), $r_{\text {eff }}$ (middle) and LWC (bottom) for the continental (left) and marine (right) case. Uncertainties are calculated from Eqs. (14-16). 
Table 1. For each microphysical variable (1st column) the table shows the mean value $\bar{x}$ with the related total uncertainty $\Delta x$ (2nd and 4 th column) and the 10th-90th percentile range of variability over the cloud lifetime (3rd and 5th column).

\begin{tabular}{lrrrr}
\hline $\begin{array}{l}\text { Microphysical } \\
\text { variable }\end{array}$ & $\begin{array}{r}\text { Continental } \\
\bar{x} \pm \Delta x\end{array}$ & $\begin{array}{r}\text { Continental } \\
\text { 10th-90th } \\
\text { percentile }\end{array}$ & $\begin{array}{r}\text { Marine } \\
\bar{x} \pm \Delta x\end{array}$ & $\begin{array}{r}\text { Marine } \\
\text { 10th-90th } \\
\text { percentile }\end{array}$ \\
\hline CDNC $\left[\mathrm{cm}^{-3}\right]$ & $382 \pm 161.58$ & $9.8-842.4$ & $25 \pm 12.2$ & $1.5-69$ \\
$r_{\text {eff }}[\mu \mathrm{m}]$ & $4.3 \pm 0.86$ & $2.9-6.5$ & $28.4 \pm 5.6$ & $11.2-42.7$ \\
$\mathrm{LWC}\left[\mathrm{g} \mathrm{m}^{-3}\right]$ & $0.19 \pm 0.03$ & $0.11-0.22$ & $0.16 \pm 0.04$ & $0.01-0.38$ \\
\hline
\end{tabular}

the mean value $\bar{x}$ with the related uncertainty $\Delta x$ (2nd and 4th column) and the variability in terms of the 10th-90th percentile range ( 3 rd and 5th column).

\section{Conclusions}

An assessment of the new technique SYRSOC (SYnergistic Remote Sensing Of Cloud) has been performed by determining the microphysics of two liquid stratocumulus clouds which formed in continental and marine air masses. The continental event occurred on the 28 May 2008 from 21:30 UTC to 24:00 UTC while the marine occurred on the 10 December 2010 from 11:00 UTC to 16:00 UTC. The mean black carbon concentration (as a proxy for pollution) during the two events was $300 \mathrm{ng} \mathrm{m}^{-3}$ and $2.5 \mathrm{ng} \mathrm{m}^{-3}$ for the continental and the marine event, respectively. The aim of the study is to provide the full cloud microphysics by applying SYRSOC to the synergistic suite of three remote sensors, namely cloud RADAR, LIDAR and MWR installed at the GAW Atmospheric Station of Mace Head, Ireland. For given vertical and temporal resolutions SYRSOC retrieves the three main microphysical variables, namely CDNC, $r_{\mathrm{eff}}$ and LWC at all heights above the cloud base and instants in time. The retrieved CDNC have been compared to the concentration of $\mathrm{CCN}$ sampled few meters above the ground level at different supersaturations. The comparison showed good matching between the retrieved number of droplets and the sampled CCN suggesting that the studied boundarylayer stratocumuli had $\mathrm{ss} \approx 0.1 \%$ for the continental and $0.1 \% \leq \mathrm{ss} \leq 0.75 \%$ for the marine case. A combined analysis of the CDNC and the $r_{\text {eff }}$ showed that whilst in marine conditions the drizzle modified the retrieval of the mean effective radius determining a large mean value $(28.4 \mu \mathrm{m})$ more than two times larger than the mode $r_{\text {eff }}(12 \mu \mathrm{m})$, in continental condition the absence of drizzle led to almost 1:1 relation between mean and mode $r_{\text {eff }}(4.3 \mu \mathrm{m}$ vs. $4.7 \mu \mathrm{m})$. Moreover, in continental conditions the spectral width of the effective DSD becomes narrower when the droplets concentration increases (dispersion index). On the contrary, the relation between the relative dispersion and the CDNC does not show correlation for the marine case most likely because the very low $\mathrm{CDNC}\left(\bar{N}=25 \mathrm{~cm}^{-3}\right)$ where the relative dispersion normally starts to decrease for CDNC $>100 \mathrm{~cm}^{-3}$. The RDF analysis showed that the RDF is mono-modal in both cases with narrow spectral width centred on $r_{\mathrm{eff}}^{\mathrm{MOD}}$ in the continental case and broad spectral width in the marine case with an extended tail at the drizzle radii. The mode radius $r_{\mathrm{eff}}^{\mathrm{MOD}}$ for the two cases confirms the Twomey theory about the dependence of the DSD on the number of droplets in the cloud. The retrieved $r_{\text {eff }}$ at the top layer of the clouds have been compared with the MODIS satellite $r_{\text {eff }}$ showing good matching: $7 \mu \mathrm{m}$ (MODIS) vs. $6.2 \mu \mathrm{m}$ (SYRSOC) and $16.3 \mu \mathrm{m}$ (MODIS) vs. $17 \mu \mathrm{m}$ (SYRSOC) for continental and marine cases, respectively.

The study of the departure function $f(z)$ and the LWC profiles shows a general subadiabatic character of both clouds with more pronounced departure in the continental case due to the shallower cloud depth and the significant mixing with dry tropospheric air.

Finally, an error analysis has been performed to assess the method accuracy. The CDNC retrieval suffers the largest uncertainty compared to $r_{\text {eff }}$ and LWC retrievals. The error-corrected values of the retrieved microphysical variables are for the continental and marine case, respectively, $382 \pm 161.58 \mathrm{~cm}^{-3}$ and $25 \pm 12.2 \mathrm{~cm}^{-3}$ for the CDNC; $4.3 \pm 0.86 \mu \mathrm{m}$ and $28.4 \pm 5.6 \mu \mathrm{m}$ for $r_{\mathrm{eff}}$; $0.019 \pm 0.035 \mathrm{~g} \mathrm{~m}^{-3}$ and $0.016 \pm 0.042 \mathrm{~g} \mathrm{~m}^{-3}$. The retrieved mean values of the microphysical variables are in agreement with the results shown by Miles et al. (2000) for continental and marine stratocumulus clouds.

Acknowledgements. The authors would like to acknowledge Herman W. J. Russchenberg and Christine Brandau from Delft University of Technology (The Netherlands) for their precious scientific support as well as David Donovan and Rob Roebeling from KNMI (The Netherlands) and Domenico Cimini from IMAA-CNR (Italy) for supplying satellite data and for the important support in their interpretation. This study was supported by the 4th Higher Education Authority Programme for Research in Third Level Institutions (HEA PRTLI4) and by EPA Ireland through the CCRP Fellowship "Research Support for Mace Head". This work was also conducted as part of COST Action ES0702 (EG-CLIMET).

Edited by: A. Kokhanovsky

\section{References}

Ackerman, A. S., Toon, O. B., Taylor, J. P., Johnson, D. W., Hobbs, P. V., Ferek, R. J.: Effects of Aerosols on Cloud Albedo: Evaluation of Twomey's Parameterization of Cloud Susceptibility Using Measurements of Ship Tracks, J. Atmos. Sci., 57, 26842695, 2000.

Albrecht, B. A., Fairall, C. W., Thomson, D. W., White, A. B., Sauder, J. B., and Schubert, W. H.: Surface-based remote sensing of the observed and adiabatic liquid water content of stratocumulus, Geophys. Res. Lett., 17, 89-92, 1990.

Atlas, D.: The estimation of cloud parameters by radar, J. Meteorol., 11, 309-317, 1954. 
Boers, R. and Mitchell, R. M.: Absorption feedback in stratocumulus clouds: Influence on cloud top albedo, Tellus, 46A, 229-241, 1994.

Boers, R., Russchenberg, H., Erkelens, J., and Venema, V.: Ground-based remote sensing of stratocumulus properties during CLARA, 1996, J. Appl. Meteorol., 39, 169-181, 2000.

Boers, R., Acarreta, J. R., and Gras, J. L.: Satellite Monitoring of the First Indirect Aerosol Effect: Retrieval of Droplet Concentration of Water Clouds, J. Geophys. Res., 111, D22208, doi:10.1029/2005JD006838, 2006.

Bohren, C. F. and Huffman, D.: Absorption and scattering of light by small particles, Wiley, New York, 530 pp., 1983.

Brandau, C. L., Russchenberg, H. W. J., and Knap, W. H.: Evaluation of ground-based remotely sensed liquid water cloud properties using shortwave radiation measurements, Atmos. Res., 96, 366-377, doi:10.1016/j.atmosres.2010.01.009, 2010.

Brenguier, J. L: Parameterization of the condensation process: A theoretical approach, J. Atmos. Sci., 48, 264-282, 1991.

Chylek, P. and Ramaswamy, V.: Simple approximation for infrared emissivity of water clouds. J. Atmos. Sci., 39, 171-177, 1982.

Chylek, P.: Extinction and liquid water content of fogs and clouds, J. Atmos. Sci., 35, 296-300, 1978.

Crewell, S. and Löhnert, U.: Accuracy of cloud liquid water path from ground-based microwave radiometry 2. Sensor accuracy and synergy, Radio Sci., 38, 8042, doi:10.1029/2002RS002634, 2003.

Dong, X., Ackerman, T. P., Clothiaux, E. E., Pilewskie, P., and Han, Y.: Microphysical and radiative properties of stratiform clouds deduced from ground-based measurements, J. Geophys. Res., 102, 23829-23843, 1997.

Dong, X. and Mace, G. G.: Profiles of low-level stratus cloud microphysics deduced from ground-based measurements, J. Atmos. Ocean. Tech., 20, 42-53, 2003.

Durkee, P. A., Noone, K. J., Ferek, R. J., Johnson, D. W., Taylor, J. P., Garrett, T. J., Hobbs, P. V., Hudson, J. G., Bretherton, C. S., Innis, G., Frick, G. M., Hoppel, W. A., O’Dowd, C. D., Russell, L. M., Gasparovic, R., Nielsen, K. E., Tessmer, S. A., Ostrom, E., Osborne, S. R., Flagan, R. C., Seinfeld, J. H., and Rand, H.: The Impact of Ship-Produced Aerosols on the Microstructure and Albedo of Warm Marine Stratocumulus Clouds. A Test of the MAST Hypothesis 1i and 1ii, J. Atmos. Sci, 57, 2554-2569, 2000.

Ferguson, J. A. and Stephens, D. H.: Algorithm For Inverting Lidar Returns, Appl. Optics, 22, 3673-3675, 1983.

Frisch, A. S., Feingold, G., Fairall, C. W., Uttal, T., and Snider, J. B.: On cloud RADAR and microwave radiometer measurements of stratus cloud liquid water profiles, J. Geophys. Res., 103, 195197, 1998.

Fox, N. I. and Illingworth, A. J.: The retrieval of stratocumulus cloud properties by ground-based cloud RADAR, J. Appl. Meteorol., 36, 485-492, 1997.

Goncalves, F. L. T., Martins, J. A., and Silva Dias, M. A.: Shape parameter analysis using cloud spectra and gamma functions in the numerical modeling RAMS during LBA Project at Amazonian region, Brazil, Atmos. Res., 89, 1-11, ISSN 0169-8095, doi:10.1016/j.atmosres.2007.12.005, 2008.

Haeffelin, M., Angelini, F., Morille, Y., Martucci, G., O’Dowd, C. D., Xueref-Rémy, I., Wastine, B., Frey, S., and Sauvage, L.: Evaluation of mixing depth retrievals from automatic profiling lidars and ceilometers in view of future integrated networks in Europe, Bound.-Lay. Meteorol., doi:10.1007/s10546-011-9643z, 2011.

Hale, G. M. and Querry, M. R.: Optical Constants of Water in the 200-nm to 200- $\mu$ m Wavelength Region, Appl. Opt., 12, 555-563, 1973.

Heese, B., Flentje, H., Althausen, D., Ansmann, A., and Frey, S.: Ceilometer lidar comparison: backscatter coefficient retrieval and signal-to-noise ratio determination, Atmos. Meas. Tech., 3, 1763-1770, doi:10.5194/amt-3-1763-2010, 2010.

Hudson, J. G., Noble, S., and Jha, V.: Stratus cloud supersaturations, Geophys. Res. Lett., 37, L21813, doi:10.1029/2010GL045197, 2010.

Illingworth, A. J., Hogan, R. J., O’Connor, E. J., Bouniol, D., Brooks, M. E., Delanoe, J., Donovan, D. P., Gaussiat, N., Goddard, J. W. F., Haeffelin, M., Klein Baltink, H., Krasnov, O. A., Pelon, J., Piriou, J. M., and van Zadelhoff, G. J.:Cloudnet - continuous evaluation of cloud profiles in seven operational models using ground-based observations, B. Am. Meteorol. Soc., 88, 883-898, 2007.

Iribarne, J. V. and Godson, W. L.: Atmospheric Thermodynamics, 1st ed., D. Reidel, 222 pp., 1973.

Kaufman, Y. J., Tanré, D., and Boucher, O.: A satellite view of aerosols in the climate system, Nature, 419, 215-223, 2002.

Klett, J. D.: Stable analytical inversion solution for processing lidar returns, Appl. Opt., 20, 211-220, 1981.

Korhonen, H., Carslaw, K. S., and Romakkaniemi, S.: Enhancement of marine cloud albedo via controlled sea spray injections: a global model study of the influence of emission rates, microphysics and transport, Atmos. Chem. Phys., 10, 4133-4143, doi:10.5194/acp-10-4133-2010, 2010.

Liljegren, J. C., Clothiaux, E. E., Mace, G. G., Kato, S., and Dong, $\mathrm{X}$.: A new retrieval for cloud liquid water path using a groundbased microwave radiometer and measurements of cloud temperature, J. Geophys. Res., 106, 14485-14500, 2001.

Lindberg, J. D., Lentz, W. J., Measure, E. M., and Rubio, R.: Lidar determinations of extinction in stratus clouds, Appl. Opt., 23, 2172-2177, 1984.

Löhnert, U. and Crewell, S.: Accuracy of cloud liquid water path from ground-based microwave radiometry 1 . Dependency on cloud model statistics, Radio Sci., 38, 8041, doi:10.1029/2002RS002654, 2003.

Löhnert, U., Turner, D. D., Crewell, S.: Ground-Based Temperature and Humidity Profiling Using Spectral Infrared and Microwave Observations. Part I: Simulated Retrieval Performance in Clear-Sky Conditions, J. Appl. Meteorol. Clim., 48, 10171032, doi:10.1175/2008JAMC2060.1, 2009.

Lu, M.-L., Sorooshian, A., Jonsson, H. H., Feingold, G., Flagan, R. C., and Seinfeld, J. H.: Marine stratocumulus aerosol-cloud relationships in the MASE-II experiment: Precipitation susceptibility in eastern Pacific marine stratocumulus, J. Geophys. Res., 114, D24203, doi:10.1029/2009JD012774, 2009.

Mason, B. J.: The physics of clouds Clarendon press, Oxford University Press, 2nd Ed., 1971.

Martucci, G., Milroy, C., O’Dowd, C. D.: Detection of Cloud Base Height Using Jenoptik CHM15K and Vaisala CL31 Ceilometers, J. Atmos. Ocean. Tech., 27, 305-318, 2010a.

Martucci, G., Matthey, R., Mitev, V., and Richner, H.: Frequency of Boundary-Layer-Top Fluctuations in Convective and Stable 
Conditions Using Laser Remote Sensing, Bound.-Lay. Meteorol., 135, 313-331, doi:10.1007/s10546-010-9474-3, 2010b.

Melchionna, S., Bauer, M., and Peters, G.: A new algorithm for the extraction of cloud parameters using multipeak analysis of cloud radar data. First application and results, Meteorol. Z., 17, 613-620, 2008.

Miles, L., Verlinde, J., and Clothiaux, E. E.: Cloud droplet size distribution in low-level stratiform clouds, J. Atmos. Sci., 57, 295$311,2000$.

Milroy, C., Martucci, G., Lolli, S., Loaec, S., Sauvage, L., XuerefRemy, I., Lavrič, J. V., Ciais, P., and O’Dowd, C. D.: On the ability of pseudo-operational ground-based light detection and ranging (LIDAR) sensors to determine boundary-layer structure: intercomparison and comparison with in-situ radiosounding, Atmos. Meas. Tech. Discuss., 4, 563-597, doi:10.5194/amtd-4563-2011, 2011.

Nussenzveig, H. M. and Wiscombe, W. J.: Efficiency factors in Mie scattering, Phys. Rev. Lett., 45, 1490-1494, 1980.

O'Dowd, C., Lowe, J. A., and Smith, M. H.: Observations and modelling of aerosol growth in marine stratocumulus - case study, Atmos. Environ., 33, 3053-3062, doi:10.1016/S13522310(98)00213-1, 1999.

Pinnick, R. G., Jennings, S. G., and Chylek, P.: Relationships Between ion, Absorption, Backscattering and Mass Content of Sulphuric Acid Aerosols, J. Geophys. Res., 85, 4059-4066, 1980.

Pinnick, R. G., Jennings, S. G., Chylek, P., Ham, C., and Grandy Jr., W. T.: Backscatter and extinction in Water Clouds, J. Geophys. Res., 88, 6787-6796, 1983.

Platnick, S.: Vertical photon transport in cloud remote sensing problems, J. Geophys. Res., 105, 22919-22935, 2000.
Pruppacher, H. R. and Klett, J. D.: Microphysics of Clouds and Precipitation, D. Reidel, 714 pp., 1978.

Ramanathan, V., Cess, R. D., Harrison, E. F., Minnis, P., Barkstrom, B. R., Ahmad, E., and Hartmann, D.: Cloud-radiative forcing and climate: results from the earth radiation budget experiment, Science, 243, 57-63, doi:10.1126/science.243.4887.57, 1989.

Richards, J. M.: A simple expression for the saturation vapour pressure of water in the range -50 to $140^{\circ} \mathrm{C}$, J. Phys. D Appl. Phys., 4, L15-L18, 1971.

Rogers, R. R. and Yau, M. K.: A Short Course in Cloud Physics, 3e, Pergamon press, 1989.

Salter, S., Sortino, G., and Latham, J.: Sea-going hardware for the cloud albedo method of reversing global warming, Philos. T. R. Soc. A, 366, 3989-4006, 2008.

Seinfeld, J. H. and Pandis, S. N.: Atmospheric Chemistry and Physics: From Air Pollution to Climate Change, 2nd edition, J. Wiley, New York, 2006.

Stephens, G. L., Tsay, S. C., Stackhouse, P. W., and Flatau, P. J.: The Relevance of the Microphysical and Radiative Properties of Cirrus Clouds to Climate and Climatic Feedback, J. Atmos. Sci., 47, 1742-1753, 1990.

Turner, D. D., Vogelmann, A. M., Austin, R., Barnard, J. C., CadyPereira, K., Chiu, C., Clough, S. A., Flynn, C. J., Khaiyer, M. M., Liljegren, J. C., Johnson, K., Lin, B., Long, C. N., Marshak, A., Matrosov, S. Y., McFarlane, S. A., Miller, M. A., Min, Q., Minnis, P., O'Hirok, W., Wang, Z., and Wiscombe, W.: Thin liquid water clouds: their importance and our challenge, B. Am Meteorol. Soc., 88, 177-190, 2007.

Twomey, S. A.: The influence of pollution on the short wave albedo of clouds, J. Atmos. Sci., 34, 1149-1152, 1977. 